\title{
High Altitude Platform Free Space Optics System Using Various Filtering Operations For Fifth Generation System
}

Hilal Adnan Fadhil ( $\boldsymbol{D}$ dr.hilal.adnan@gmail.com )

Alfarabi Colleges: Al-Farabi College https://orcid.org/0000-0002-8130-9004

\section{SARA RAAD}

Alfarabi Colleges: Al-Farabi College

hassan ahmed

Prince Sattam bin Abdulaziz University

median Z.

Prince Sattam bin Abdulaziz University

Waqas Al-Imitiz

University of Engineering and Technology

\section{Research Article}

Keywords: HAP, FSO, 5G, Optical Filters, BER

Posted Date: February 19th, 2021

DOI: https://doi.org/10.21203/rs.3.rs-214280/v1

License: (9) This work is licensed under a Creative Commons Attribution 4.0 International License.

Read Full License

Version of Record: A version of this preprint was published at Optical and Quantum Electronics on August 7th, 2021. See the published version at https://doi.org/10.1007/s11082-021-03139-9. 


\title{
High Altitude Platform Free Space Optics System Using Various Filtering Operations For Fifth Generation System
}

\author{
Hilal A. Fadhil ${ }^{1 *}$, Sara Raad Qasim ${ }^{1}$, Hassan Yousif Ahmed ${ }^{* 2}$, Medien Zeghid ${ }^{2,3}$, Waqas \\ A.Imtiaz
}

Corresponding Author: Hilal A. Fadhil (ORCID: 0000-0002-8130-9004)

${ }^{1 *}$ Department of Computer Engineering, Al-Farabi University College, Baghdad, Iraq

(Corresponding Author email: hilaladnan@alfarabiuc.edu.iq)

${ }^{1}$ Department of Computer Engineering, Al-Farabi University College, Baghdad, Iraq (email address: sararaad.cac@gmail.com)

${ }^{2}$ Electrical Engineering Department, College of Engineering at Wadi Aldwaseer, Prince Sattam Bin Abdulaziz University, KSA. (email address : hassanuofg@gmail.com)

${ }^{3}$ Electronics and Micro-Electronics Laboratory (E. $\mu$. E. L), Faculty of Sciences, University of Monastir, Tunisia (email address : medienzeghid@gmail.com)

${ }^{4}$ Department of Electrical Engineering, Jalozai Campus, University of Engineering and Technology, Pakistan (email address: ww.imtiaz1985@ieee.org) 


\section{Abstract:}

This paper presents high altitude platform free space optics (HAP-FSO) channels using various filtering operations for fifth generation (5G) system. Performance analysis is done utilizing different types of optical filters such as Bessel, Trapezoidal, Gaussian and Rectangular. A comparison is carried out between our proposed scheme and reported counterpart. HAP-FSO performances have been investigated by referring to different factors such as transmission distance, transmitting aperture diameter, beam divergence, transmitter aperture diameter, and receiver diameter. Simulation analysis is carried out in highly recognized software tool called Optisystem to validate the implementation and performance of the proposed system. It is found that the most extreme quality services can be accomplished via utilizing Gaussian optical channel in comparison with distinctive optical channels. Simulation results also confirm the proposed system for error free transmission at bit error rate (BER) of $10^{-9}$ for all types of filters at $10 \mathrm{Gbps}$ with in favor to Gaussian filter for the same number of users.

Keywords: HAP, FSO, 5G, Optical Filters, BER

\section{1- Introduction:}

It is expected that the high altitude platform free space optics (HAP-FSO) could be a modern innovation in photonics industries. This innovation makes it conceivable to collect the received optical channels via the FSO link under ultra-high throughput transmission rate. This method decreases the trouble while deploying optical filaments [1-3]. The HAP-FSO system offers wide unique properties in terms of free range, straightforward establishment, and transmission security. Lasers and (Light Emitting Diodes) LEDs are utilized as sources; both are broadly 
utilized for long-haul and short-haul communication individually. Low earth orbit and small satellites orbit are their practical applications.

The method identifies application where a temporary channel is a fundamental for a communication network especially for the case of a drop in a standing communication [4-6]. The present portable clients need more reliable multi-services and faster data speeds. The 5G promises to convey that, and much more. One of the proposed solutions for achieving ultra-high data rate can be implemented by using FSO system [7]. This massive data rate offered by FSO system is considered as infrastructure for future technologies. Among them 5G technology which handles maximum throughput at much higher speeds up to 50 Gbps than the today's traditional cellular with more number of active users producing demanded for high data rates [7].

An FSO beam divergence is one of the significant factors which can adjust the signal-to-noise ratio (SNR) for cellular base stations that identifies the most efficient data-delivery route to a particular user. Also, it helps to reduce the interference for nearby active users by sending individual data packets in many different directions. In our analysis, we have proposed several ways to implement the FSO in 5G networks. Optical filters considered as components that mitigate noise power less than $(-45 \mathrm{dBm})$ as much as possible to allow only the desired data with a limited bandwidth to pass from transmitter to receiver. Depending on the application and the system performance, filters regarded as a key for $5 \mathrm{G}$ enabling technology that provides quality of service and reliability. Other parameters are the FSO antennas aperture with differential feeding, which maintains a high gain and wide bandwidth compared with conventional RF aperture antennas. 
Many applications have been investigated such as visible light communication, infrared data acquisitions, and inter-satellite communication to satisfy user demands [4-6]. Today's, 5G network is proposed using the radio-over-fiber channel which has been employed in various methods such as cellular architecture 5G, millimeter wave 5G communications, and 5G backhaul wireless network [7-9]. As data capacity and processing resources transfer into the cloud, this issue required data centers for storage and data transfer capacity. Key elements driving higher limit server farm interconnect data transfer capacity include Broad bandpass filters to transmit the entire O-band, C-band or L-band. Optical filters are the premier solution for HAP-FSO application to ensure faultless signal transmission, dependable results, cost-effectiveness and exceptional service quality for optical communication systems. Filters have the ability to block all unwanted ambient wavelengths and pass only the necessary wavelength output while increasing transmit power and resolution. Optical filters can help to achieve a more stable, accurate system. Many types of optical filters are available such us Rectangular, Trapezoidal, Gaussian and Bessel filters. In order to select the best filter, we have investigated various types of optical filters needed to overcome the main drawback we had currently having in terms of transmission distance, bit-error rate (BER) and received power. One of the most common filters used for enhancing proposed systems is a bandpass filter. To discover the best bandpass filter according to the proposed HAP-FSO application, we have used an array of laser light source and a bandpass optical filter to highlight various wavelengths to be collected at the receiver side. In this work, the HAP-FSO using various 5G frequency bands is designed and investigated. Moreover, its framework exhibitions with different affecting factors such as transmission distance, receiver diameter, transmitter aperture diameter, and beam divergence have been analyzed. Further analysis is investigated for various filtering signal processing with the help of 
numerical equations of the transfer function of various filters. The rest of this paper is organized as follows. Section 2 describes the $5 \mathrm{G}$ system design with and without optical filter process. Section 3 presents the findings of proposed system. Section 4 introduces feasibility of FSO-5G system. Finally, the conclusions are drawn in Section 5.

\section{2- 5G System Design}

\subsection{Without and with optical filter process}

The essential diagram based on HAP-FSO system is shown in Fig.1, which presents the transmitter, HAP-FSO link, and the receiver part, indicated by detection and Low-pass filter (LPF). The Semiconductor Optical Amplifier (SOA) is mainly employed under long-haul transmission distance. Table 1 shows the system parameters adopted in our analysis, to design the optical receiver, four various types of optical filters have been utilized. The proposed platform is considered as a standard with respect to $5 \mathrm{G}$ optical network, to prove the effectiveness in the new $5 \mathrm{G}$ network which employing under the same optical parameter $[7,8]$.

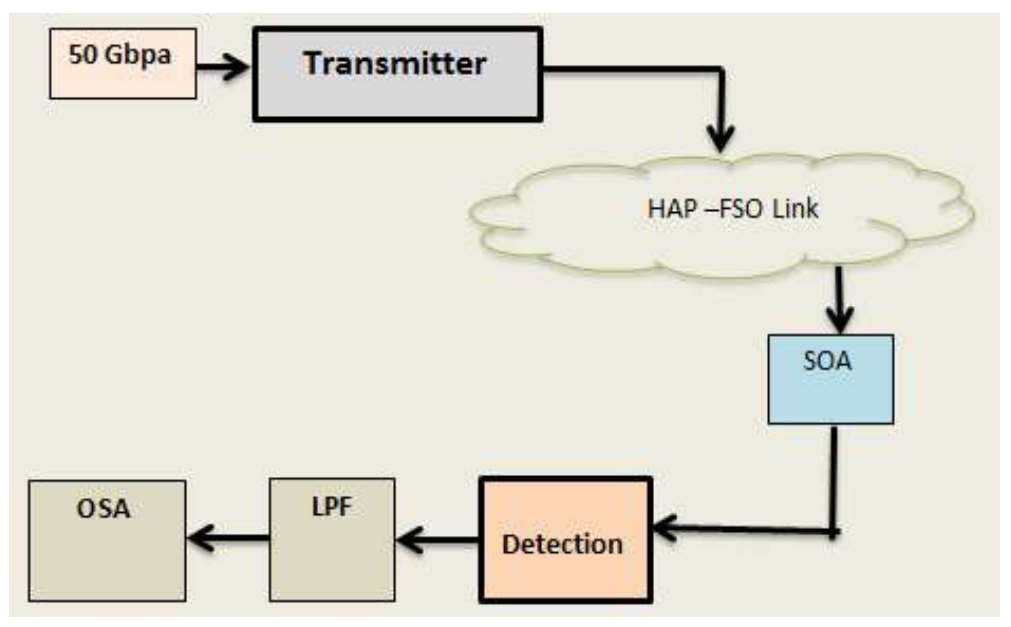

Figure 1 HAP-FSO Block diagram without optical filter 
Table 1: System parameters

\begin{tabular}{|c|c|c|}
\hline \multicolumn{2}{|r|}{ Parameter } & Value \\
\hline \multicolumn{2}{|c|}{ Typical Application / Data Protocol } & Fiber Channel and HAP-FSO / \\
\hline & HAP altitude $(\mathrm{H})$ & $50 \mathrm{~km}$ \\
\hline & Wind velocity (w) & $22 \mathrm{~m} / \mathrm{s}$ \\
\hline & Refractive index parameter $\left(\mathrm{A}_{\mathrm{o}}\right)$ & $1.75 \times 10^{-14} \mathrm{~m}^{-2 / 3}$ \\
\hline \multirow{5}{*}{ Transmitter } & Light Source & Lasers \\
\hline & Wavelength $(\lambda)$ & $1550 \mathrm{~nm}$ \\
\hline & Zenith angle $\left(\Theta_{z}\right)$ & $(0 \sim \pi / 2)$ \\
\hline & Transmit Aperture Diameter $\left(\mathrm{T}_{\mathrm{AD}}\right)$ & $(10-17) \mathrm{cm}$ \\
\hline & Total Output Power & $20 \mathrm{dBm}$ \\
\hline \multirow{2}{*}{ Receiver } & Detector/ Sensitivity & $\mathrm{APD} /-48 \mathrm{dBm}$ \\
\hline & Receive Aperture Diameter $\left(\mathrm{R}_{\mathrm{AD}}\right)$ & $(15-22) \mathrm{cm}$ \\
\hline
\end{tabular}

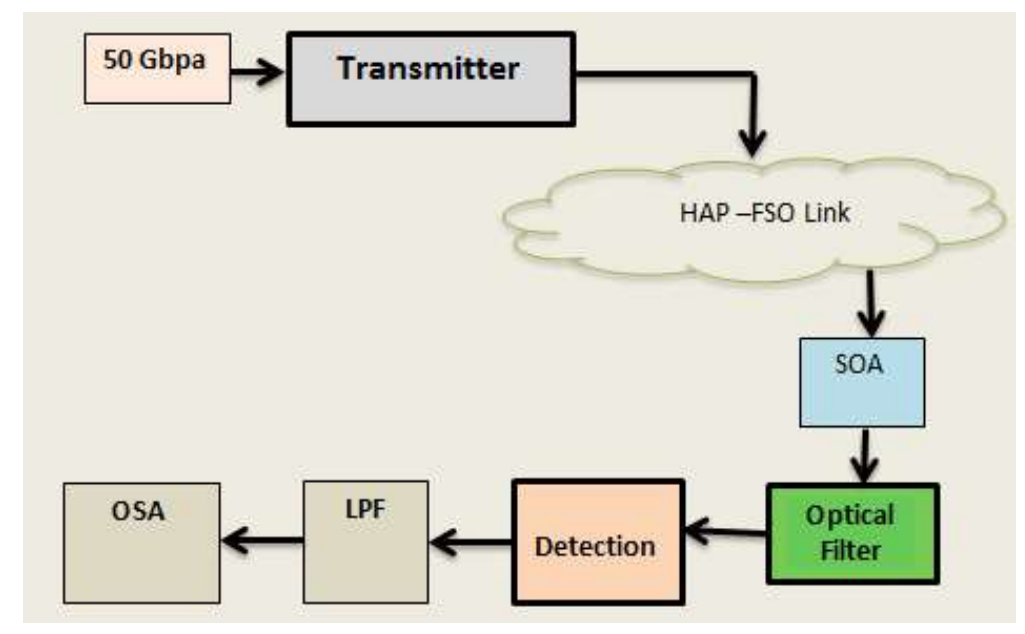

Figure 2 HAP-FSO Block diagram with optical filter

Similarly, Figure 2 shows the modified system designed with the optical filters. The signal is transmitted via the optical-satellite link and it first amplified using the SOA. The light source 
used is Spatial CW laser with various power levels according to environment condition. Then the optical filter is used to reconstruct the signal according to filter shape. Different optical filters can be utilized, namely Gaussian optical filter, Bessel optical filter, Trapezoidal optical filter, and Rectangular optical filter. The filtered signal is detected using the photo-detector and filtered before transferring to the optical spectrum analyzer (OSA) to analyze the optical spectrum which displays an eye diagram and threshold. The transfer function $\mathrm{H}(f)$ of each filters used have been presented in Table 2 [5].

Table 2: Proposed Optical Filters Transfer function

\begin{tabular}{|c|c|}
\hline Optical Filter Type & Transfer function $\mathrm{H}(\mathrm{f})$ \\
\hline Gaussian filter & $\propto e^{-\ln \sqrt{2}\left(\frac{2\left(f-f_{o}\right)^{2 N}}{B}\right)}$ \\
\hline Bessel filter & $\propto \frac{d_{o}}{B_{N}(s)}$ \\
\hline Trapezoidal filter & $\propto 10^{\left(\frac{1-A}{10 B-B_{0 d B}}\right)}\left(f-f_{o}\right)$ \\
\hline Rectangular Filter & $\propto\left(\frac{1-R}{\left.1-R * e^{2 \pi l\left(\frac{f-f_{o}}{B}\right)}\right)}\right.$ \\
\hline
\end{tabular}

where $\mathrm{H}(f)$ is the filter transfer function, $\alpha$ is the insertion loss, $f_{\mathrm{o}}$ is the filter center frequency, $\mathrm{B}$ is the filter bandwidth, $\mathrm{B}_{0 \mathrm{~dB}}$ is the zero $\mathrm{dB}$ bandwidth, and $\left(\mathrm{d}_{\mathrm{o}}, A\right.$, and $R$ )are filter constant for Bessel filter, trapezoidal, and Rectangular filters, respectively[5].

\section{Results and Discussion}

In our analysis, Four (4) optical filters can be used, namely Bessel optical filter, Trapezoidal optical filter, Gaussian optical filter, and Rectangular optical filter. For each case of utilized filter, the next filter can be replaced with the other three optical filters too. Figure 2 shows the 
proposed system that has been designed with the integration of optical filters, the received signal is first amplified using the optical amplifier, and then the amplified signal is filtered. At the receiver part, the filtered signal is detected using the photo-detector and filtered before giving to the Bit Error Rate (BER) analyzer. Meanwhile, the optical spectrum analyzers can be used to analyze the optical spectrum of each filter type in terms optical signal-to-noise ratio (OSNR). The received optical signal has been measured via power meter represents the power received in $\mathrm{dBm}$. The BER analyzer automatically calculates the BER value, displays an opening eye diagram including the threshold level. The channel used for transmitting the optical signal has been configured via FSO medium, the clear weather has been assumed throughout the study. The HAP-FSO system investigated in Fig. 2 has a significant impact on the whole system performance specially the BER value. Figures 3-8 show the simulated results that have been analyzed the BER value as a function of transmission distance, aperture diameter, and beam divergence. 


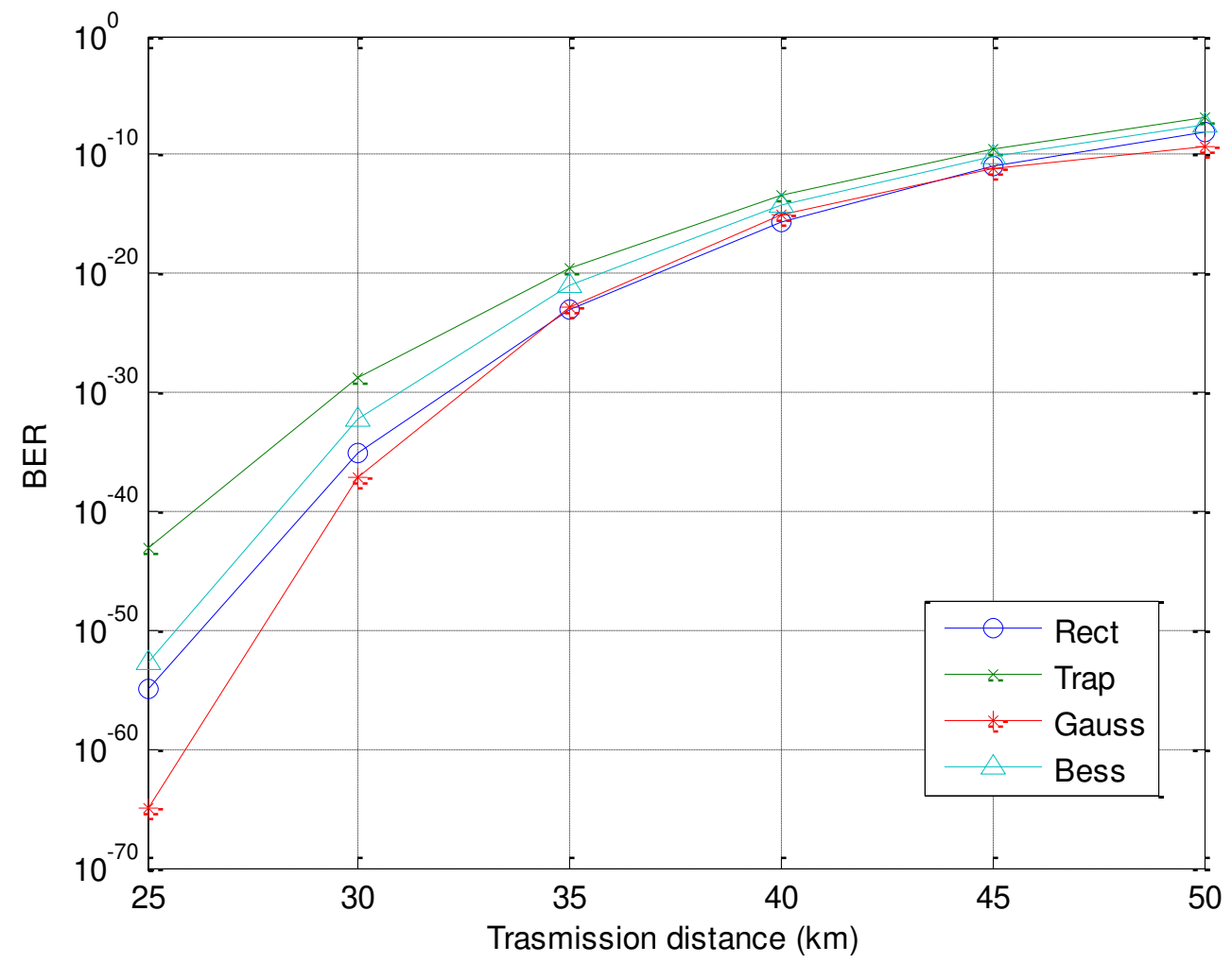

Figure 3 Minimum BER value versus Transmission distance $(\mathrm{km})$ for HAPS range applications using various optical filters

Figure 3 shows the bit error rate (BER) versus the transmission distance for different types of optical filters. As long as fiber increases a larger dispersion and attenuation increase as well, thus increasing the bit error rate. In can be seen from the figure Gaussian filter has better performance over other filters at the same condition of transmission. Figs. 4-5 depict the relation between minimum BER and aperture diameter at the transmitter and receiver part. It is seen that with the expanding aperture diameter, the minimum BER value is diminished for various optical filters. The Gaussian filter has accomplished better outcomes than the other filter types. 


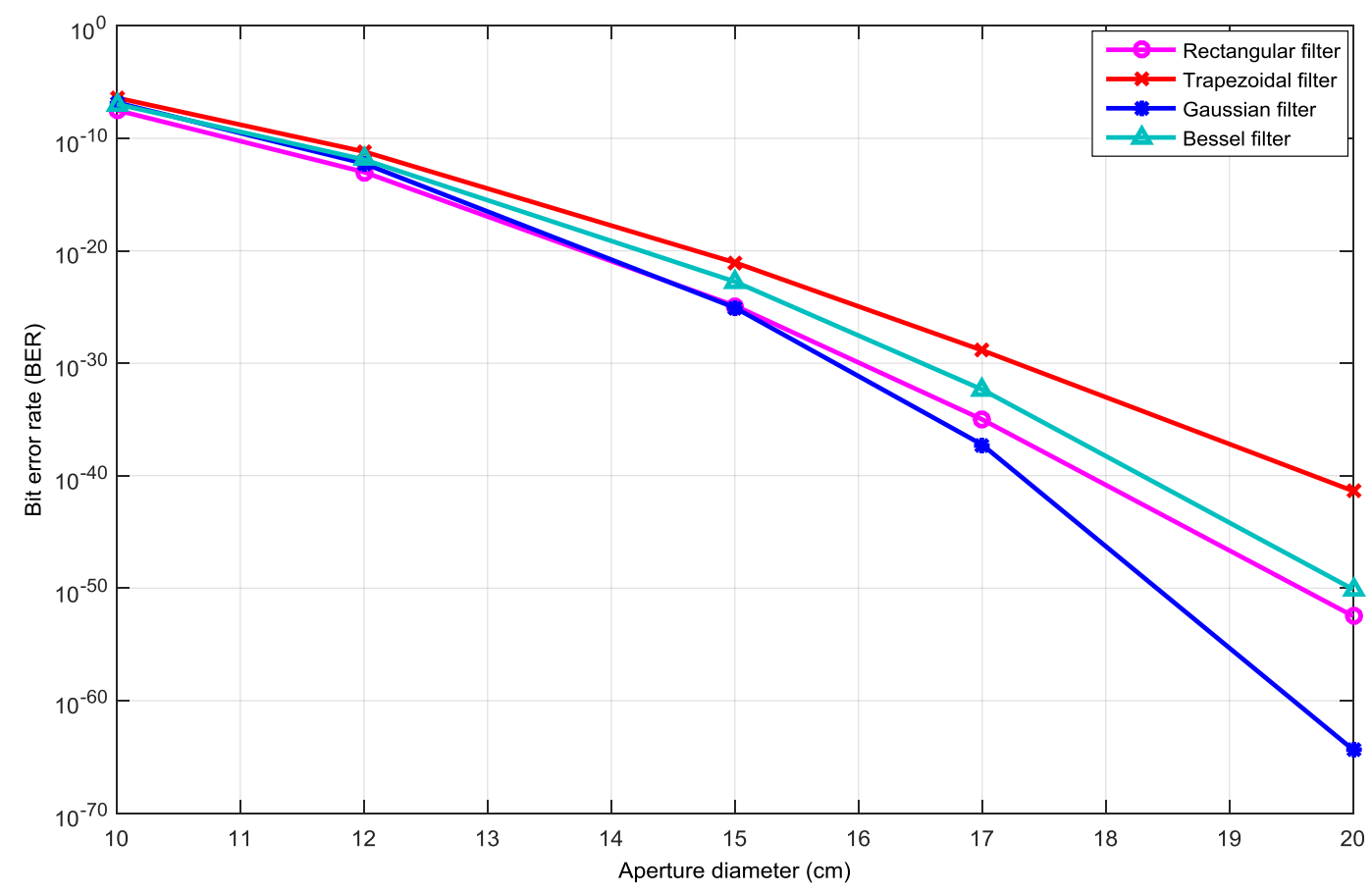

Figure 4 Minimum BER value versus transmitting aperture diameter for HAP-FSO system.

Figure 6 presents the relationship between minimum BER and beam divergence. It is seen that with the expanding beam divergence, minimum BER value is increased for all type of filters. But the rectangular filter achieved better results compared with other types of filters. 


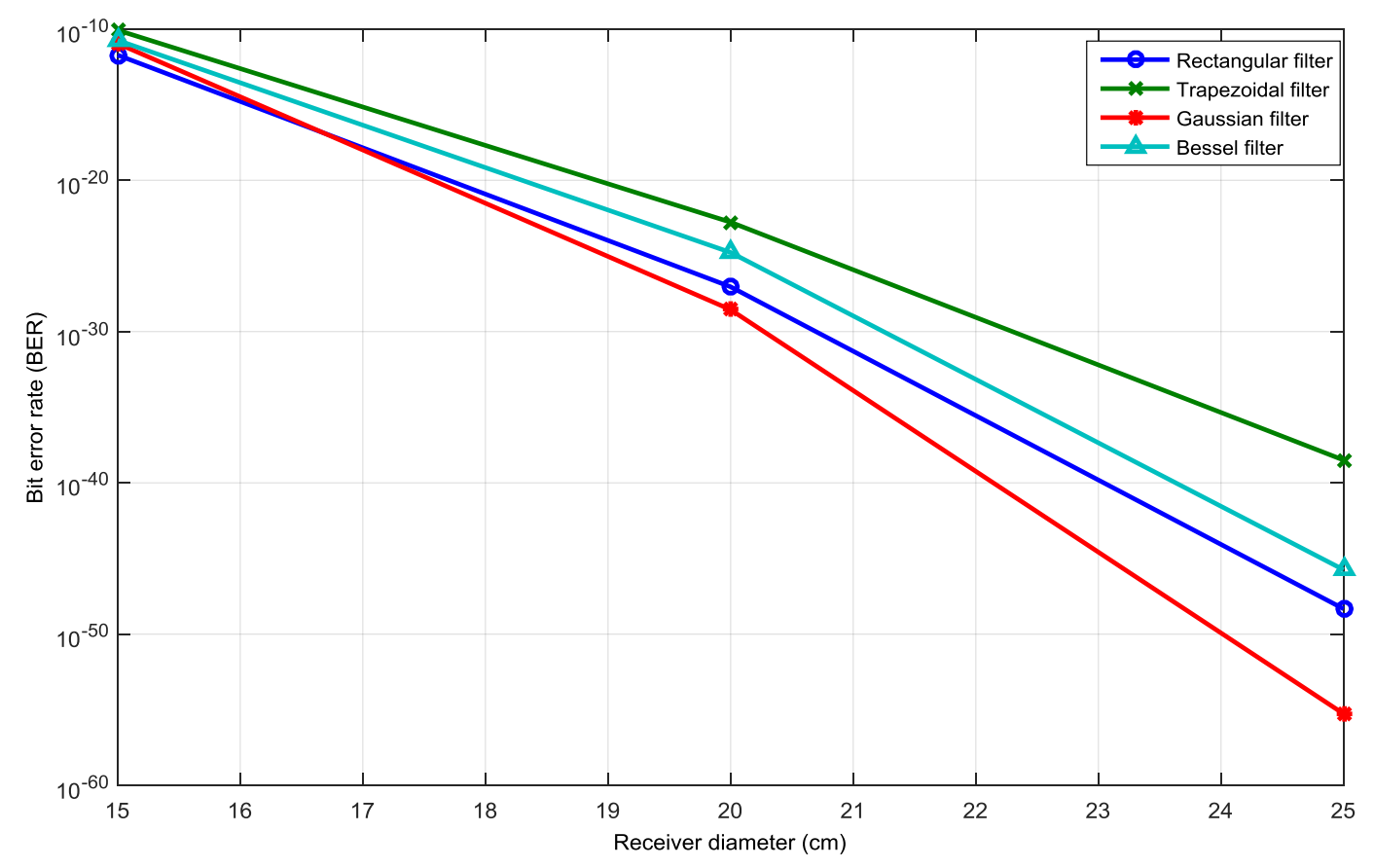

Figure 5 Minimum BER value versus receiver aperture diameter for HAP-FSO system.

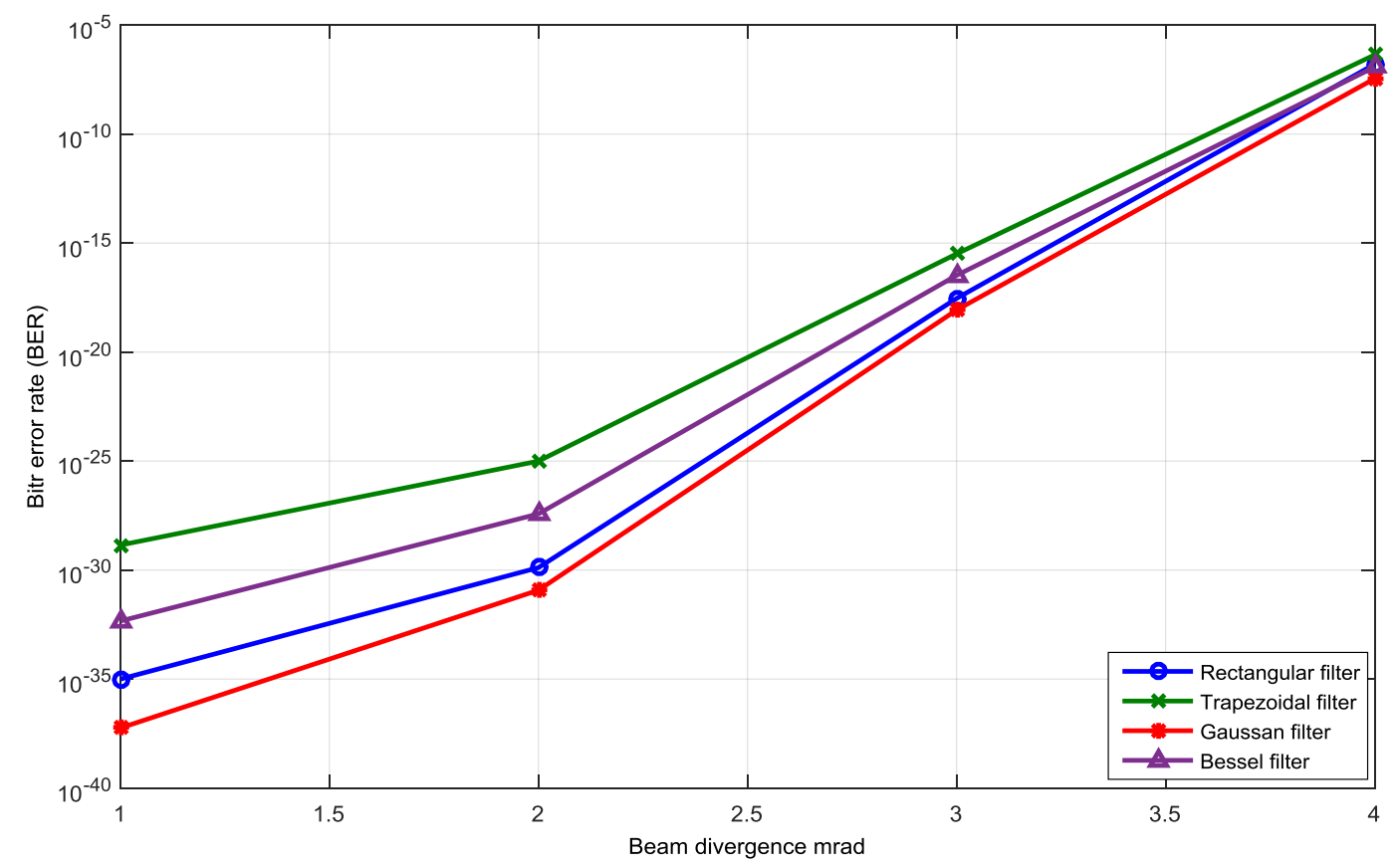

Figure 6 Minimum BER value versus beam divergence for HAPS range applications using different optical filters. 
Figure 7 simulates the minimum value of BER as a function of data rate using trapezoidal filter optical filter; it has been seen that among the worst case of all optical filters, the trapezoidal filter optical filter has a significant impact compared with the previous modal (without optical filter).

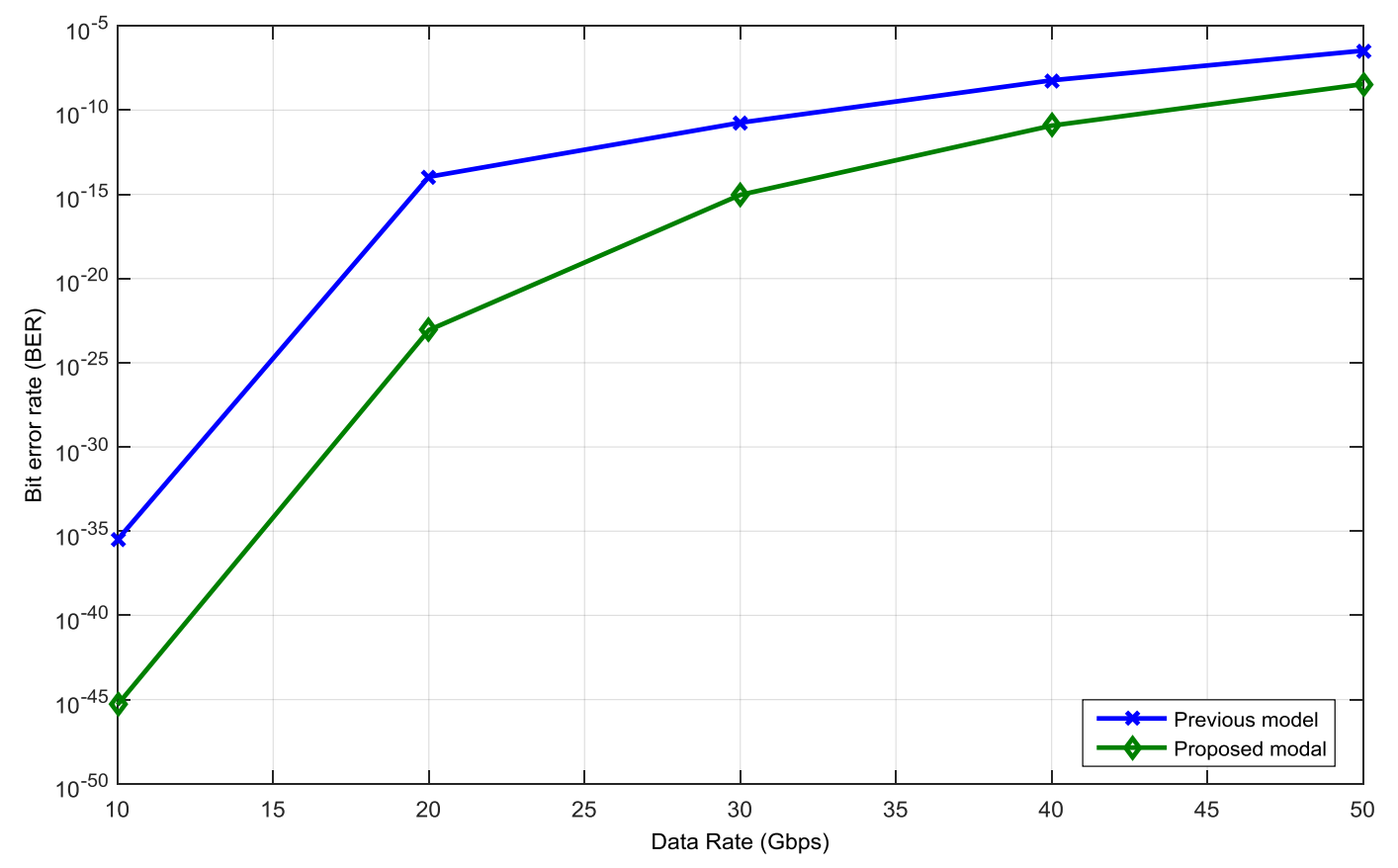

Figure 7 Minimum BER value versus data rate for 5G range applications using previous modal (without optical filter).

Figure 8 shows the relationship between throughput and bandwidth for $5 \mathrm{G}$ frequency band based various optical filters. The $5 \mathrm{G}$ frequency band is divided into low-band (400 MHz-1 GHz), medium band $(1 \mathrm{GHz}-30 \mathrm{GHz})$, and high band $(30-60 \mathrm{GHz})$. It can be seen that as the frequency band increases the maximum throughput data is increased as well for all band levels. Higher data rate can be achieved when employing a Gaussian filter over other types of filters. 


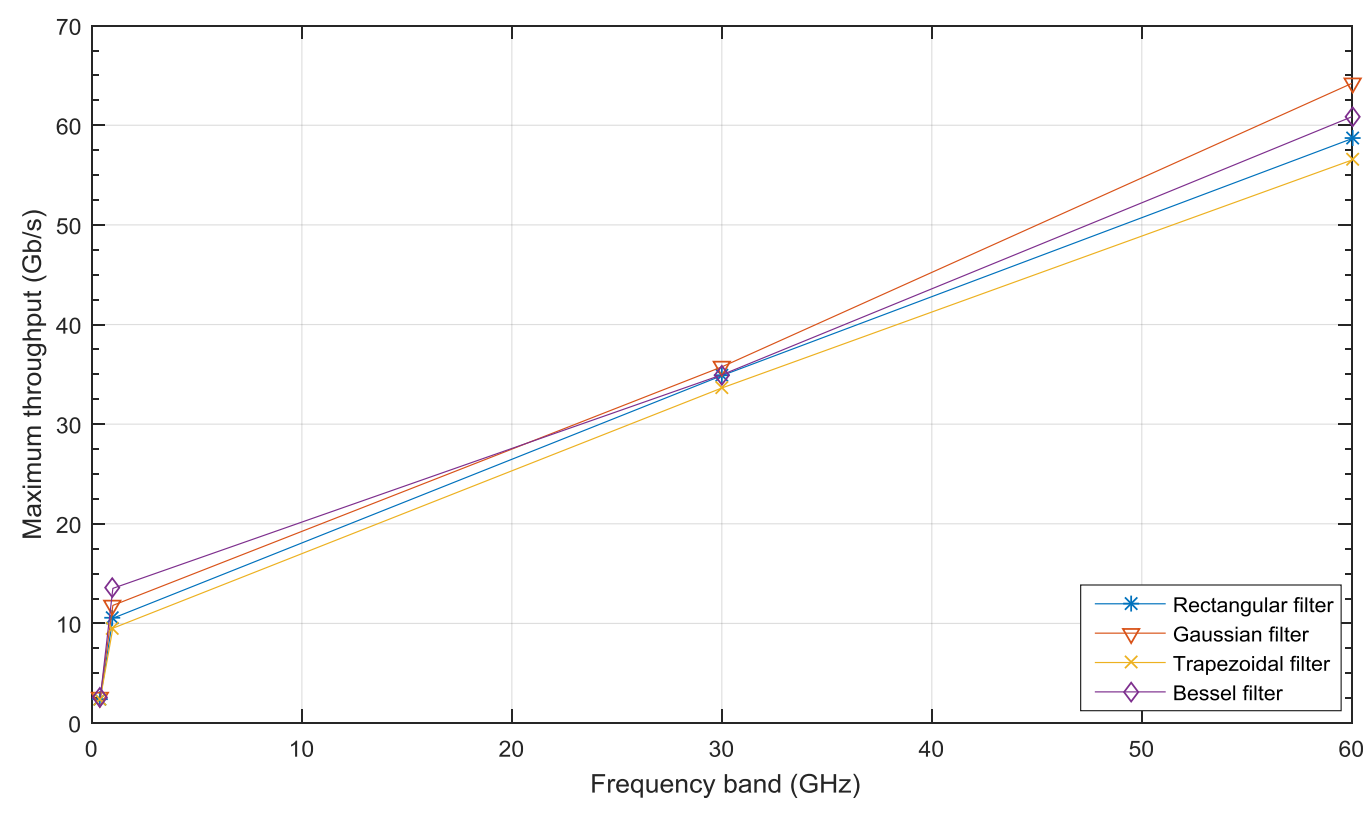

Figure 8: Throughput versus frequency band

Figures 9-12 show the optical data waveforms as a function of received power for the four types of optical filters via OSA. It is seen that the received power in all filter types are almost the same which is $-20 \mathrm{dBm}$ whereas the OSNR is $37.91 \mathrm{~dB}, 33.90 \mathrm{~dB}, 34.04$ and $33.95 \mathrm{~dB}$ for Rectangular, Trapezoidal, Gaussian and Bessel filters, respectively. Also, noise power has been measured as $-60 \mathrm{~dB},-56 \mathrm{~dB},-56.34 \mathrm{~dB}$, and $-56.26 \mathrm{~dB}$ for rectangular, Trapezoidal, Gaussian and Bessel filters, respectively. 


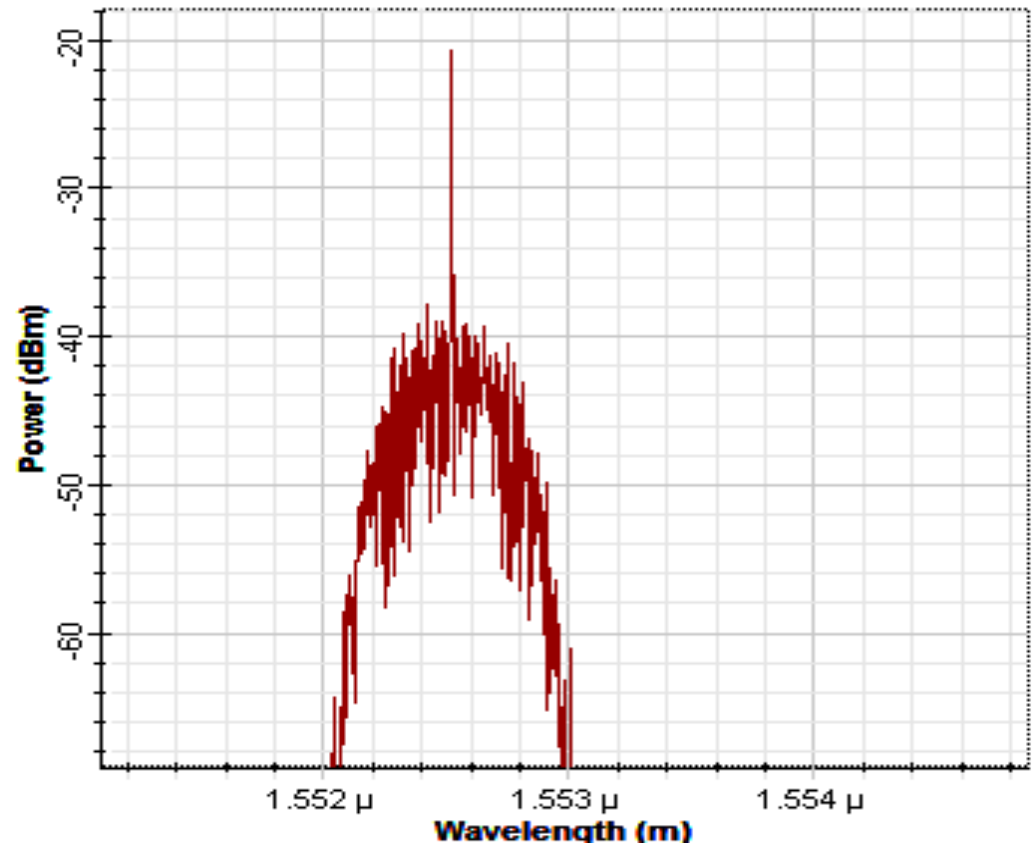

Figure 9 Rectangular optical filter received power versus wavelength.

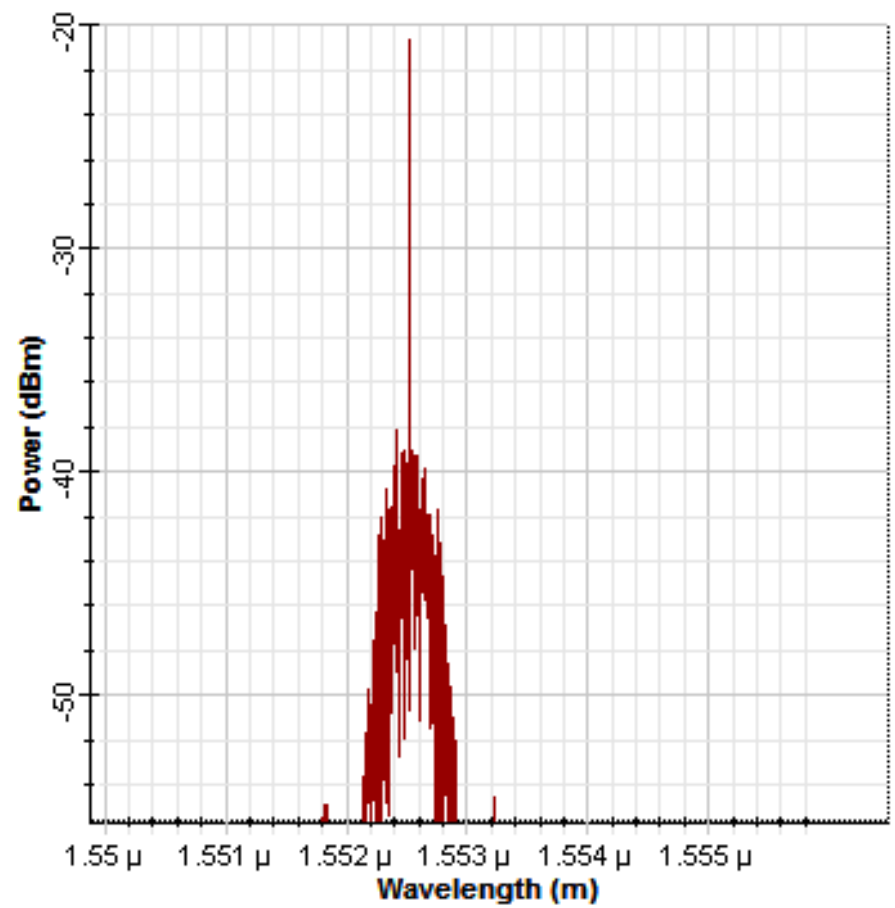

Figure 10 Trapezoidal optical filter received power versus wavelength. 


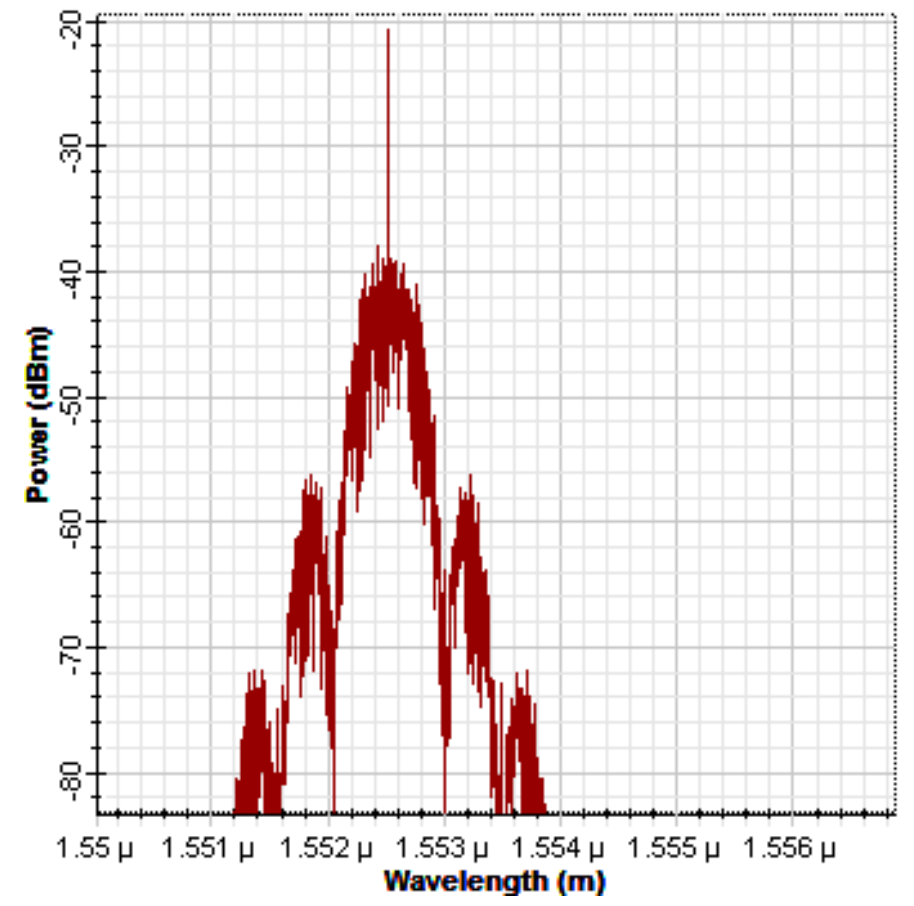

Figure 11 Gaussian optical filter received power versus wavelength.

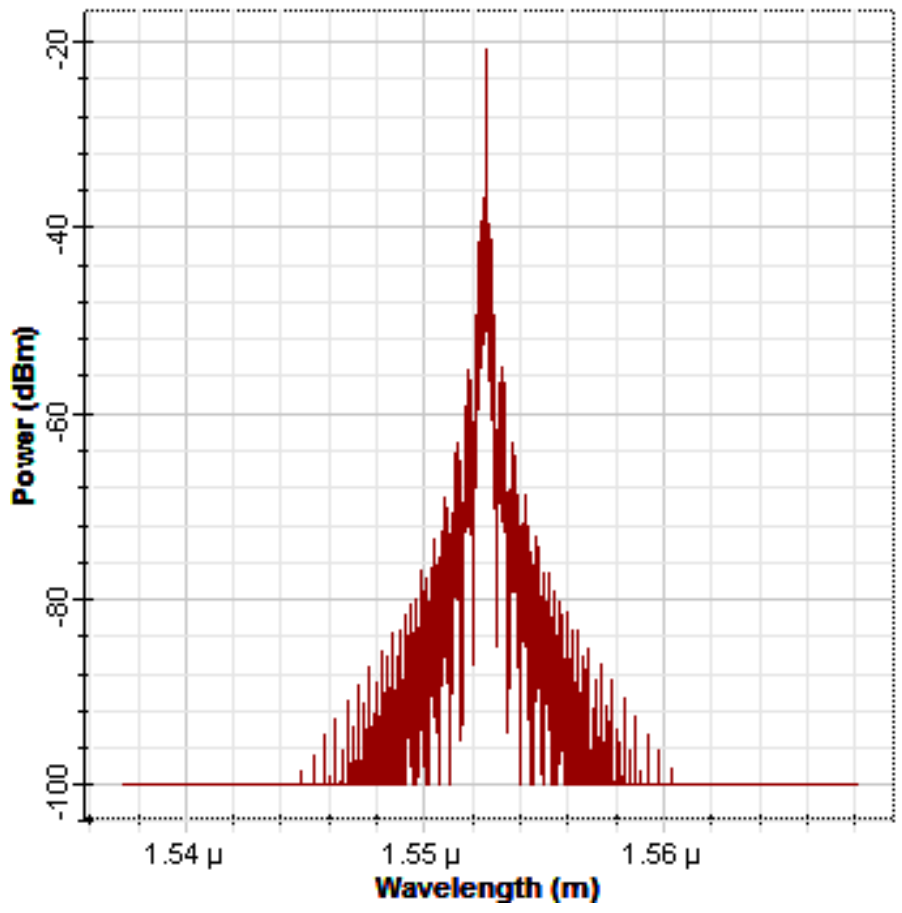

Figure 12 Bessel optical filter received power versus wavelength. 


\section{Feasibility of FSO-5G system}

Past decade have witnessed a multi-fold increase in the requirement of bandwidth due to the proliferation of data communicating devices. Now every person in a household, education institute, or office carries multiple devices including smart phones, smart watches, laptops, and tablets etc. All these devices are connected to the Internet and consumes data through numerous applications. Furthermore, introduction of Internet of Things (IoTs) have evolved the mode of communication such that Internet is no longer used to connect humans but is also facilitating communication between machines and devices [10-15]. All these factors have not only multiplied the demand for bandwidth, but also created a very dense network of interconnected devices that requires a very large and dense Access network connecting these devices to the core or backhaul network. The existing $3 \mathrm{G}$ and $4 \mathrm{G}$ networks, rely on base stations and large cells that cover a few kilometers of distance to provide connectivity. However, the current solution might soon exhaust owing to the exponential growth of devices and bandwidth requirement. In the said reference, the deployment of communication networks have shifted towards small cells that are deployed everywhere and connect devices to the core network. 5G systems, employing such a large density network, are expected to provide broadband high speed connections of up to 20 Gbps [12]. 5G networks are designed to provide set of application that differs from the existing communication networks including, but not limited to, mobile broadband connectivity, mission critical application, massive IoTs applications, smart grids, etc. Furthermore, 5G networks are likely to give rise to a new class of applications that do not exist today but can take advantage of the underlying network features including latency, bandwidth and coverage [11-12].

However, provision of small scale interconnections, ubiquitous computing, and high speed connectivity will require more cell towers to be installed. 5G cell planning is expected to be 
ultra-dense with 40-50 towers per Kilometer square [12]. Consequently, a major shift in network architecture is necessary that encompasses the use of centralized Radio Access Networks (CRANs). Fig. 13 describes schematic diagram about potential application of FSO link in 5G networks. The CRANs utilizes cloud based network architecture that facilitates the separation of Remote Radio Heads (RRH) from the Baseband units (BBU) and provides centralized BBUs. The connectivity between the BBU and the RRH is referred to as front haul networks [11, 13].

The massive deployment of RRH in order to provide the services promised by $5 \mathrm{G}$ networks makes the front hauling complex [11,13]. Furthermore, deployment of such a large number of RRHs will increase the utilization of optical fiber media by 10 -folds that entail heavy civil work and massive capital expenditure (CAPEX) [13, 15]. Moreover, deployment of optical fiber media in densely populated localities is second to impossible. Traditional microwave and RF links cannot be employed in such scenarios owing to high data rate requirements of $5 \mathrm{G}$ network. Consequently, free space optical (FSO) communication is a suitable candidate to provide the required high speed connectivity with relative less complexity. Since 5G technology uses new frequency bands that are well above those traditionally used for 4G LTE, and above the range, a new mechanism should be adopted in terms of filtering process to support higher frequencies required by mm Wave. 


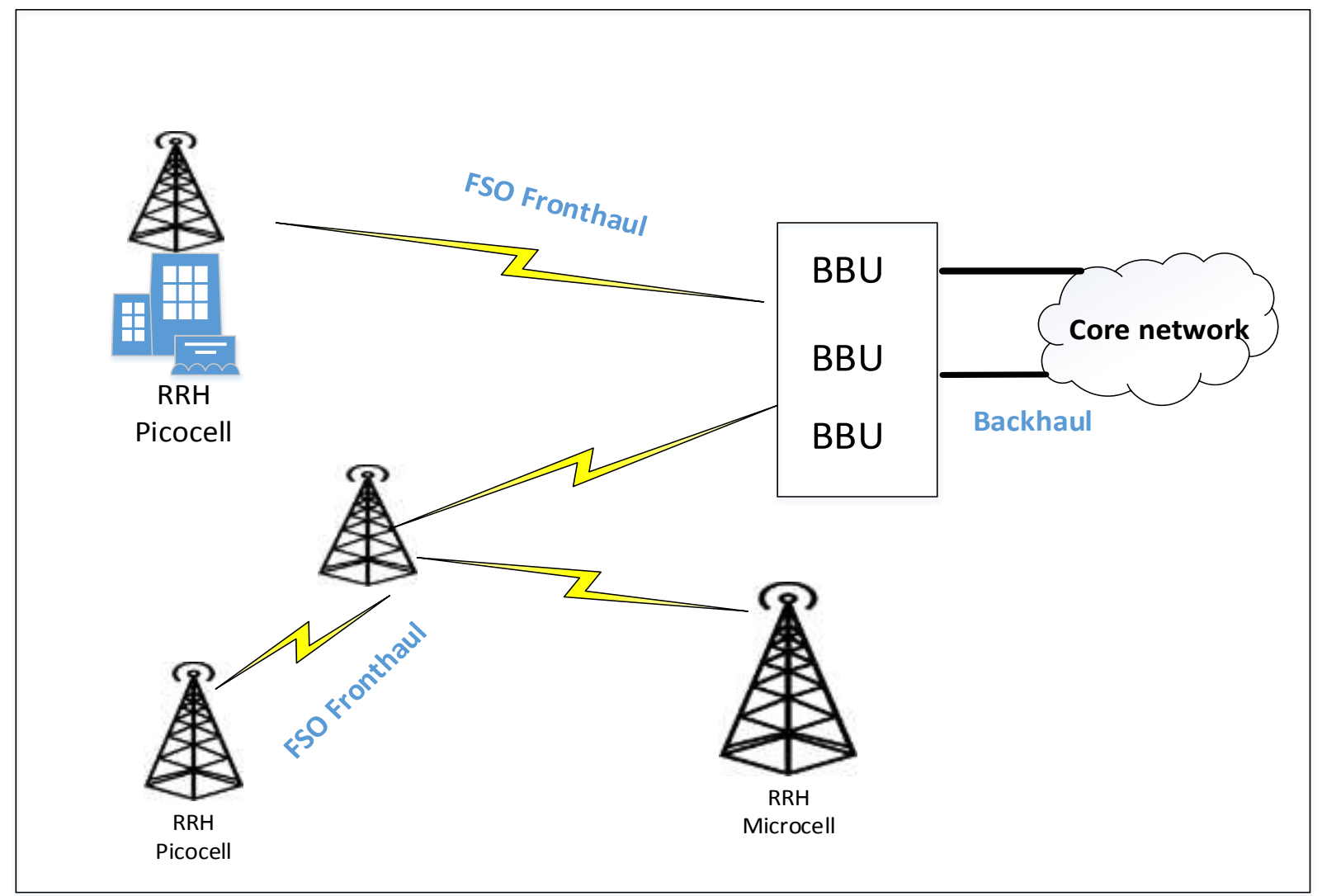

Figure 13 Application of FSO link in 5G networks

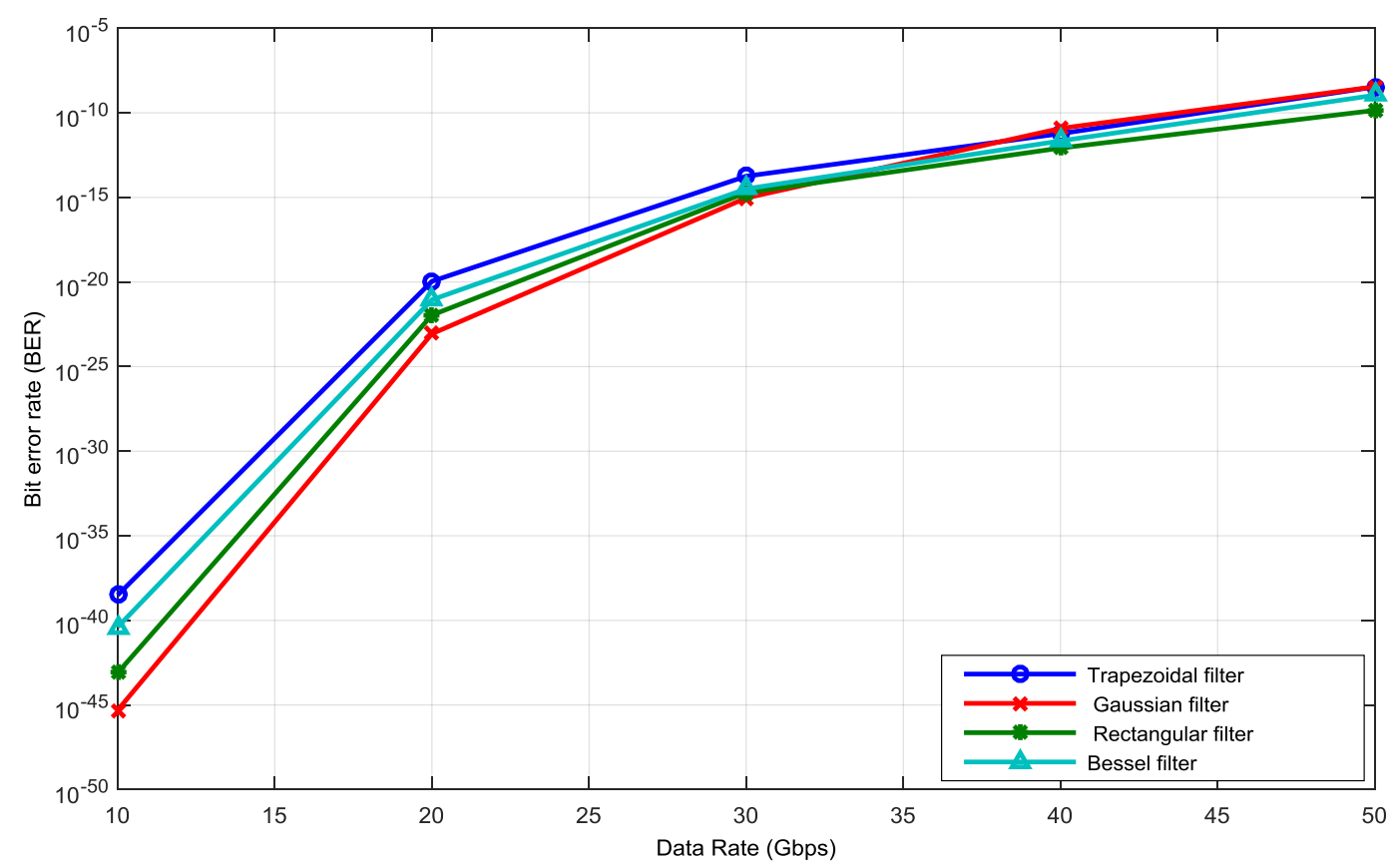

Figure 14 Minimum BER value versus data rate for 5G range applications using different optical filters. 
The simulated results with respect to the input laser power present the comparative system performances of different optical filters as a function BER and data rate. Figure 14 shows the relation between minimum BER and data rate. It is observed that with increasing data rate up to 5G coverage range application, minimum BER value is increased for all type of filters. But the trapezoidal filter achieved better results compared with other types of filters.

\section{Conclusion}

A practical way to achieve $5 \mathrm{G}$ network standard requirement under FSO backbone is to select an efficient filtering processing. Such filters are evolving to support higher frequencies and increased bandwidth with ever increasing performance. In particular, the proposed system was analyzed for various filtering signal processing: Bessel, Trapezoidal, Gaussian and Rectangular. The HAP-FSO based 5G system communication is studied in which its system performances under various factors such as transmission distance, transmitting aperture diameter, beam divergence, transmitter aperture diameter, receiver diameter have been investigated. It is observed that with increasing data rate up to $5 \mathrm{G}$ coverage range application, minimum BER value is increased for all type of filters. But the trapezoidal filter achieved better results compared with other types of filters.

\section{References}

[1] Roy R, Babu JS. Simulation and performance analysis of free space optical systems using multiple TX/RX and polarized CO-OFDM techniques under atmospheric disturbances. Int J Eng Res: Gen Sci 2015;3(1):743-9.

[2] Noor NHM, Naji AW, Al Khateeb W. Performance analysis of a free space optics link with multiple transmitters/receivers. IIUM Eng J 2012;13(1):49-58.

[3] Jyoti D, Kaur B, Singh K. Light polarized coherent OFDM free space optical system. Int J Inf Comput Technol 2014;4(14):1367-72. 
[4] Sushank VS. High speeds CO-OFDM-FSO transmission system. Optik, Int J Light Electron Opt 2014;125(6):1761-3.

[5] Bouchet, O.: Free Space Optics: Propagation and Communication. Wiley Press, London (2006)

[6] Chaudhary, S., Amphawan, A.: The role and challenges of free space optical systems. J. Opt. Commun.35(4), 327-334 (2014)

[7] M. Alzenad, M. Z. Shakir, H. Yanikomeroglu and M.-S. Alouini, "FSO-based vertical backhaul/fronthaul framework for 5G+ wireless networks", IEEE Commun. Mag., vol. 56, no. 1, pp. 218-224, Jan. 2018

[8] Dios, F., Rubio, J., Rodrfguez, A., Comern, A.: Scintillation and beam-wander analysis in an optical ground station satellite uplink. Appl. Opt. 43(19), 3866-3873 (2004)

[9] Fidler, F., Knapek, M., Horwath, J., Leeb, W.R.: Optical communications for high-altitude platforms. IEEE J. Sel. Topics Quantum Electr. 16(5), 1058-1070 (2010).

[10] Kulshreshtha, P., \& Garg, A. K. (2020, July). Managing 5G Networks-A Review of FSO Challenges and Solutions. In 2020 11th International Conference on Computing, Communication and Networking Technologies (ICCCNT) (pp. 1-4). IEEE.

[11] Esmail, M. A., Ragheb, A. M., Fathallah, H. A., Altamimi, M., \& Alshebeili, S. A. (2019). 5G-28 GHz signal transmission over hybrid all-optical FSO/RF link in dusty weather conditions. IEEE Access, 7, 24404-24410.

[12] Zhang, H., Dong, Y., Cheng, J., Hossain, M. J., \& Leung, V. C. (2016). Fronthauling for 5G LTE-U ultra-dense cloud small cell networks. IEEE Wireless Communications, 23(6), 48-53.

[13] Feng, D., Sun, W., \& Hu, W. (2017, May). Hybrid radio frequency and free space optical communication for 5g backhaul. In 2017 IFIP/IEEE Symposium on Integrated Network and Service Management (IM) (pp. 616-619). IEEE.

[14] Li, C. Y., Lu, H. H., Chou, C. R., Hsia, H. M., Feng, C. Y., Chen, Y. H., ... \& Nainggolan, A. (2020). A Flexible Bidirectional Fiber-FSO-5G Wireless Convergent System. Journal of Lightwave Technology.

[15]https://www.mobileworldlive.com/zte-updates-2019-20/wdm-pon-a-key-innovation-to-enable-5gftthconverged-gigaband-access/ 
Figures

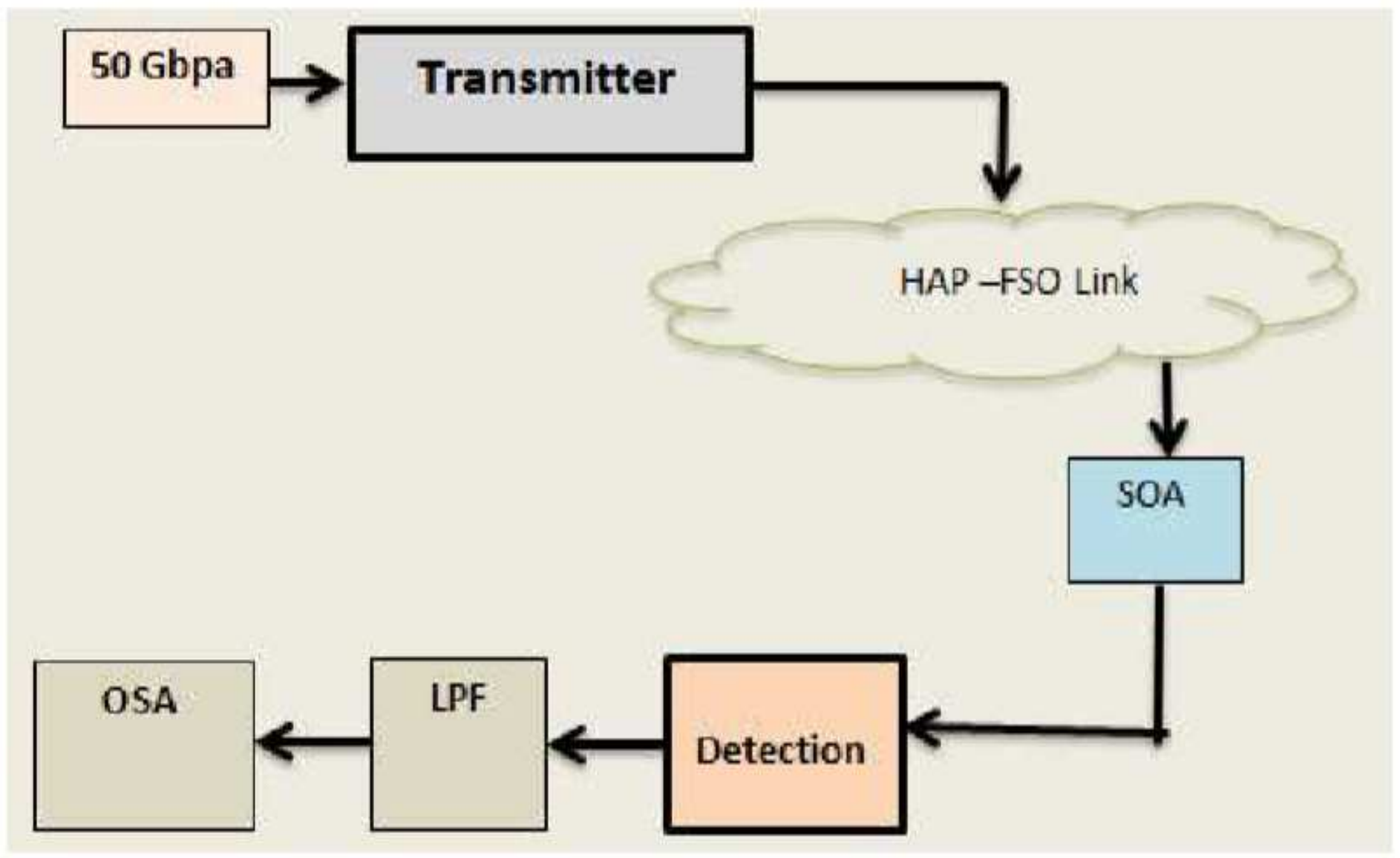

Figure 1

HAP-FSO Block diagram without optical filter 


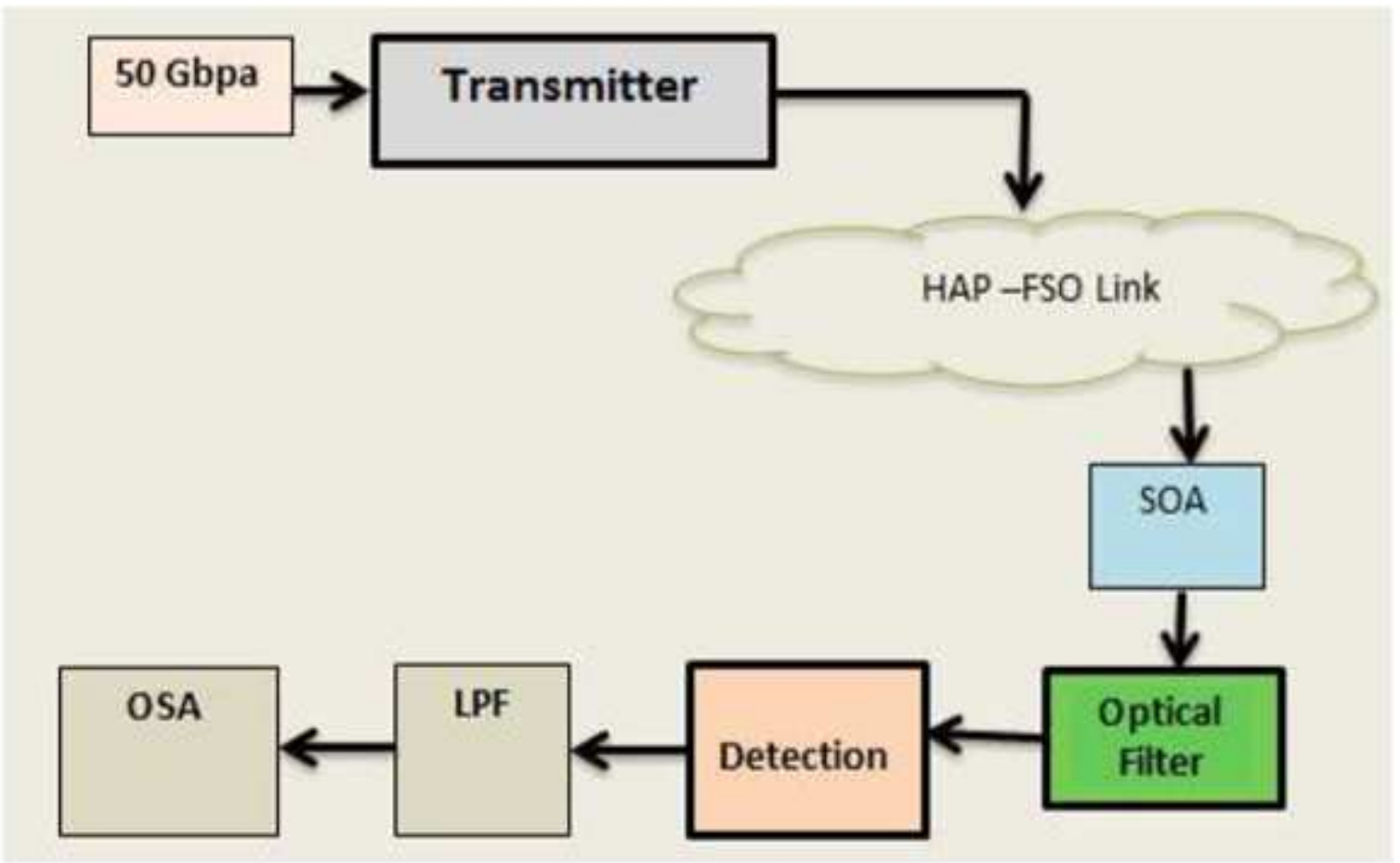

Figure 2

HAP-FSO Block diagram with optical filter 


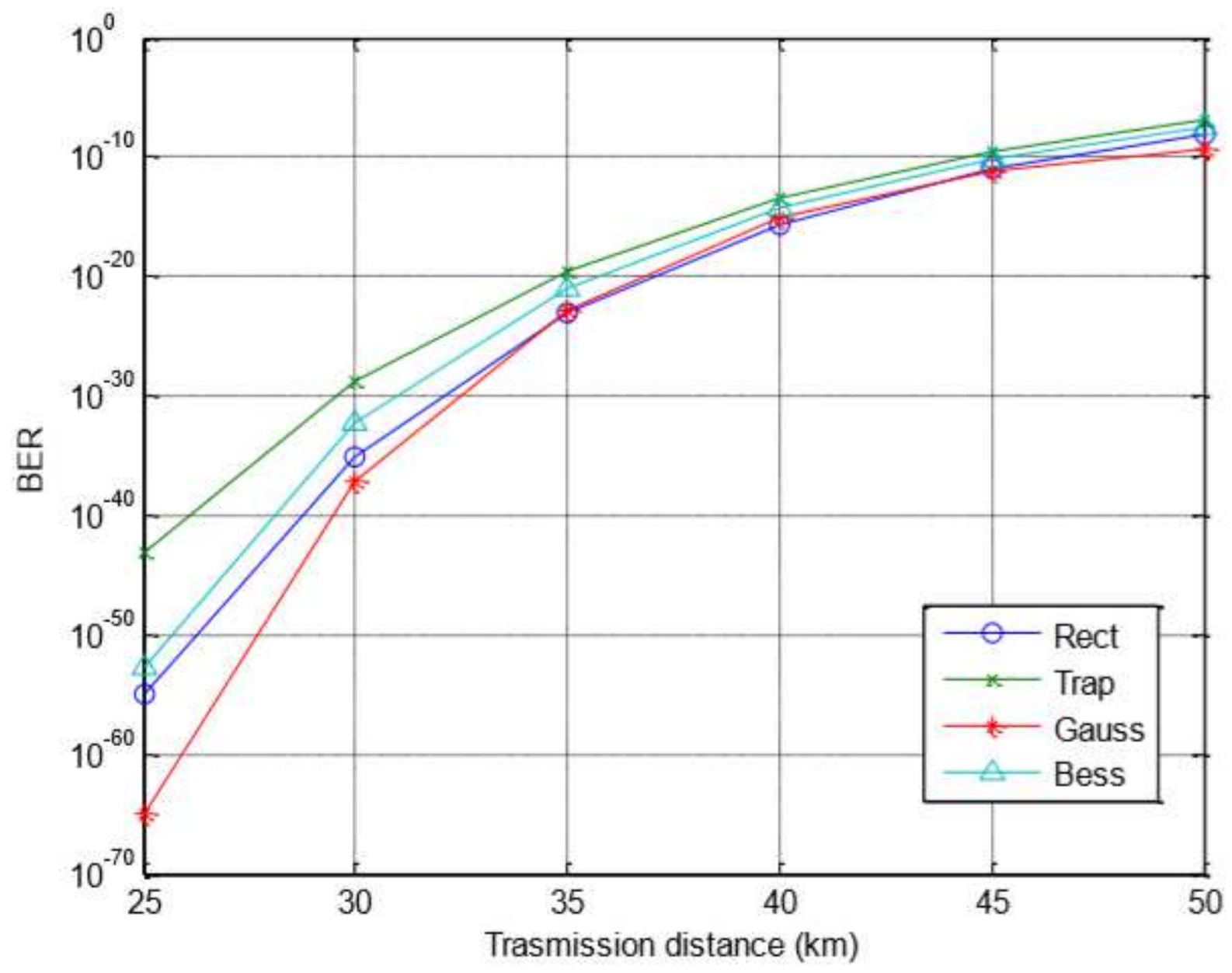

Figure 3

Minimum BER value versus Transmission distance $(\mathrm{km})$ for HAPS range applications using various optical filters 


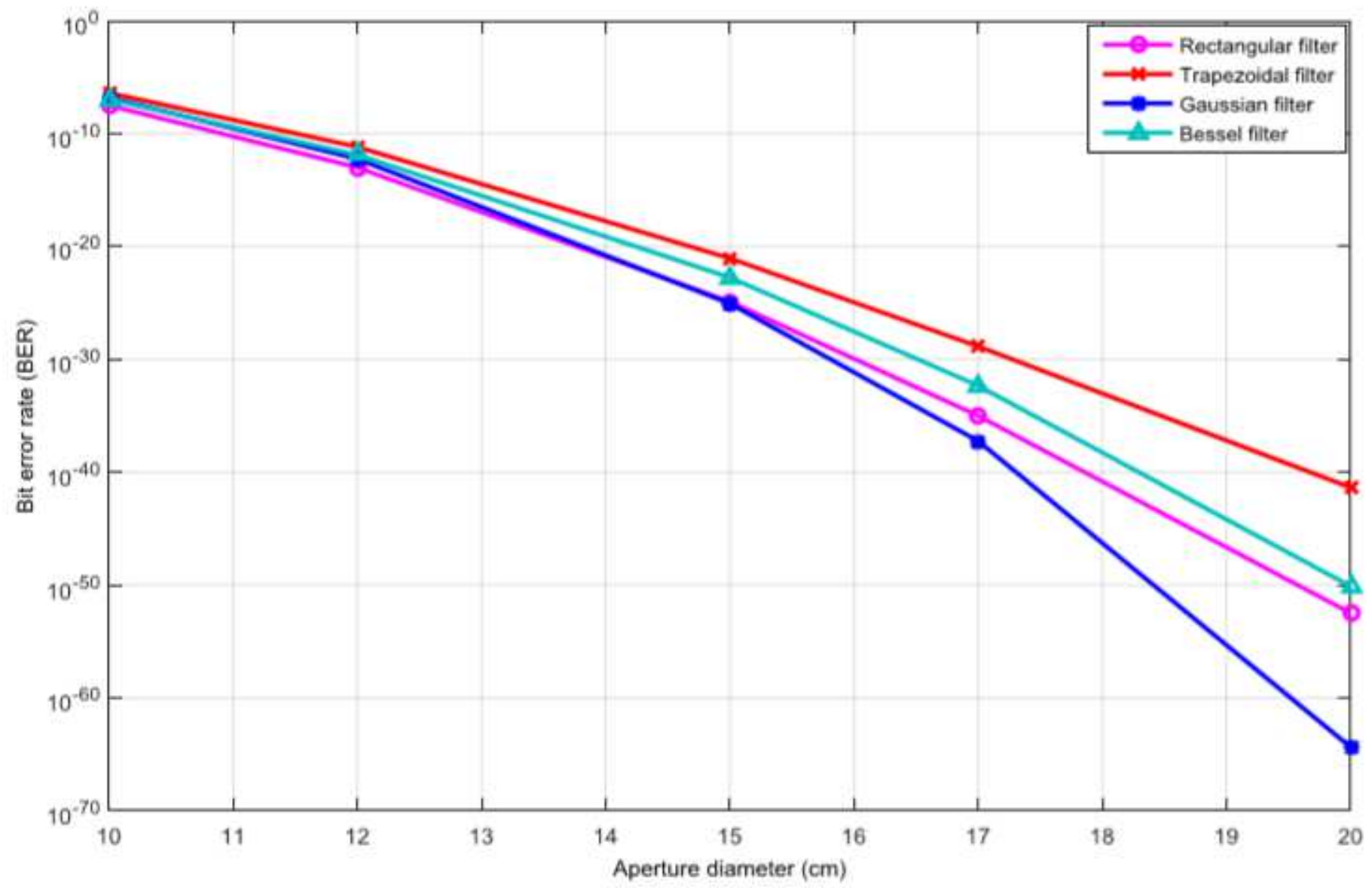

\section{Figure 4}

Minimum BER value versus transmitting aperture diameter for HAP-FSO system. 


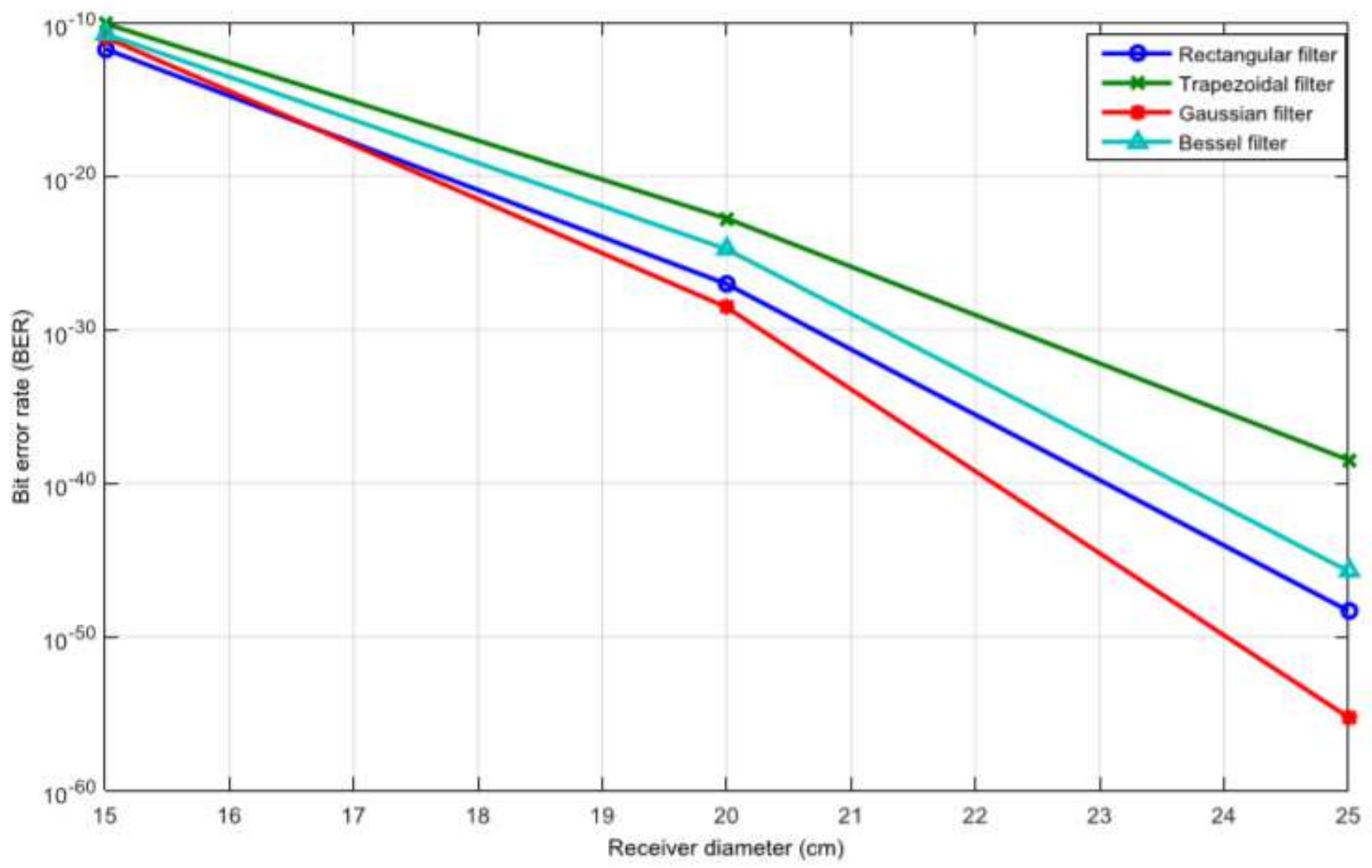

Figure 5

Minimum BER value versus receiver aperture diameter for HAP-FSO system 


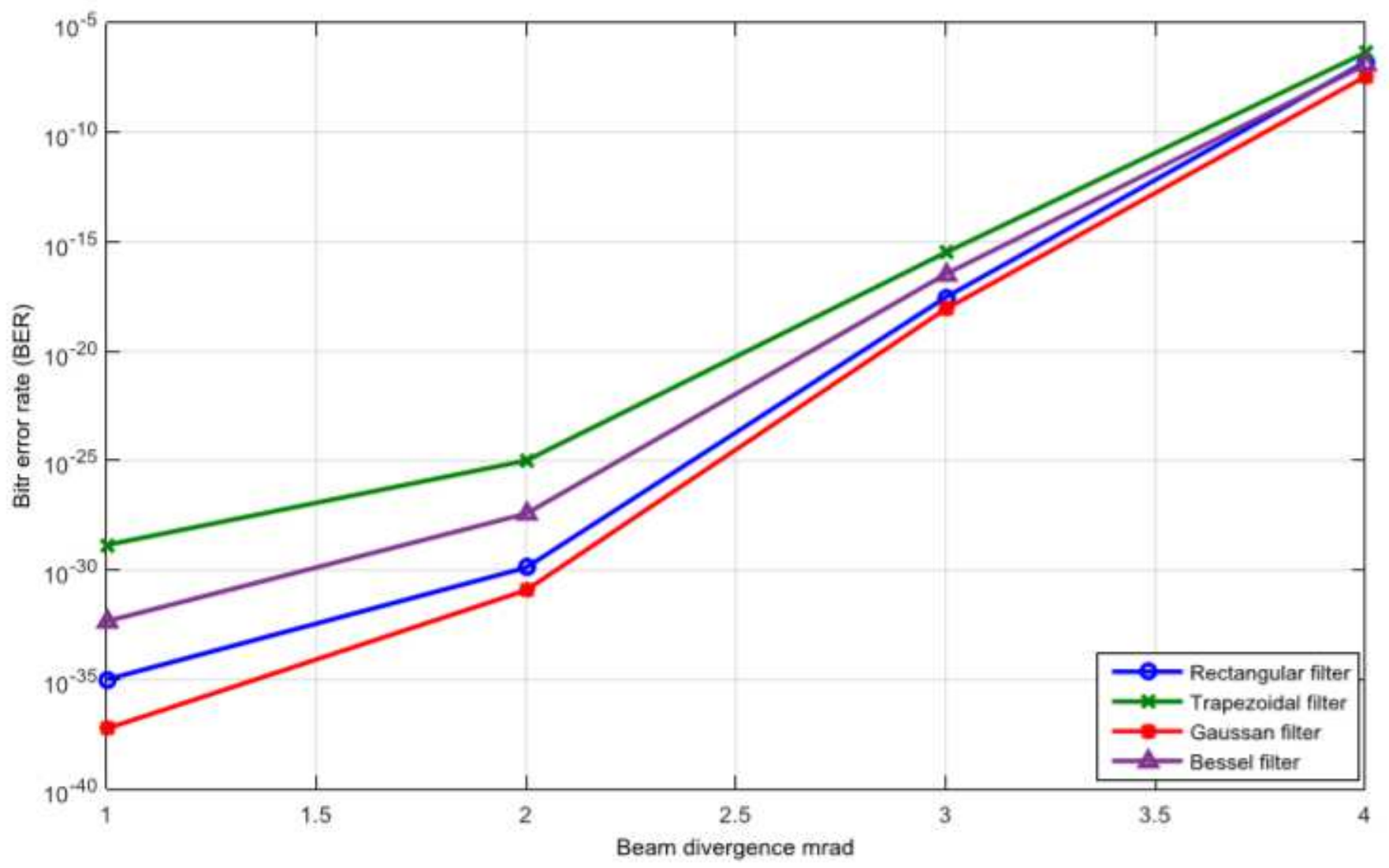

Figure 6

Minimum BER value versus beam divergence for HAPS range applications using different optical filters. 


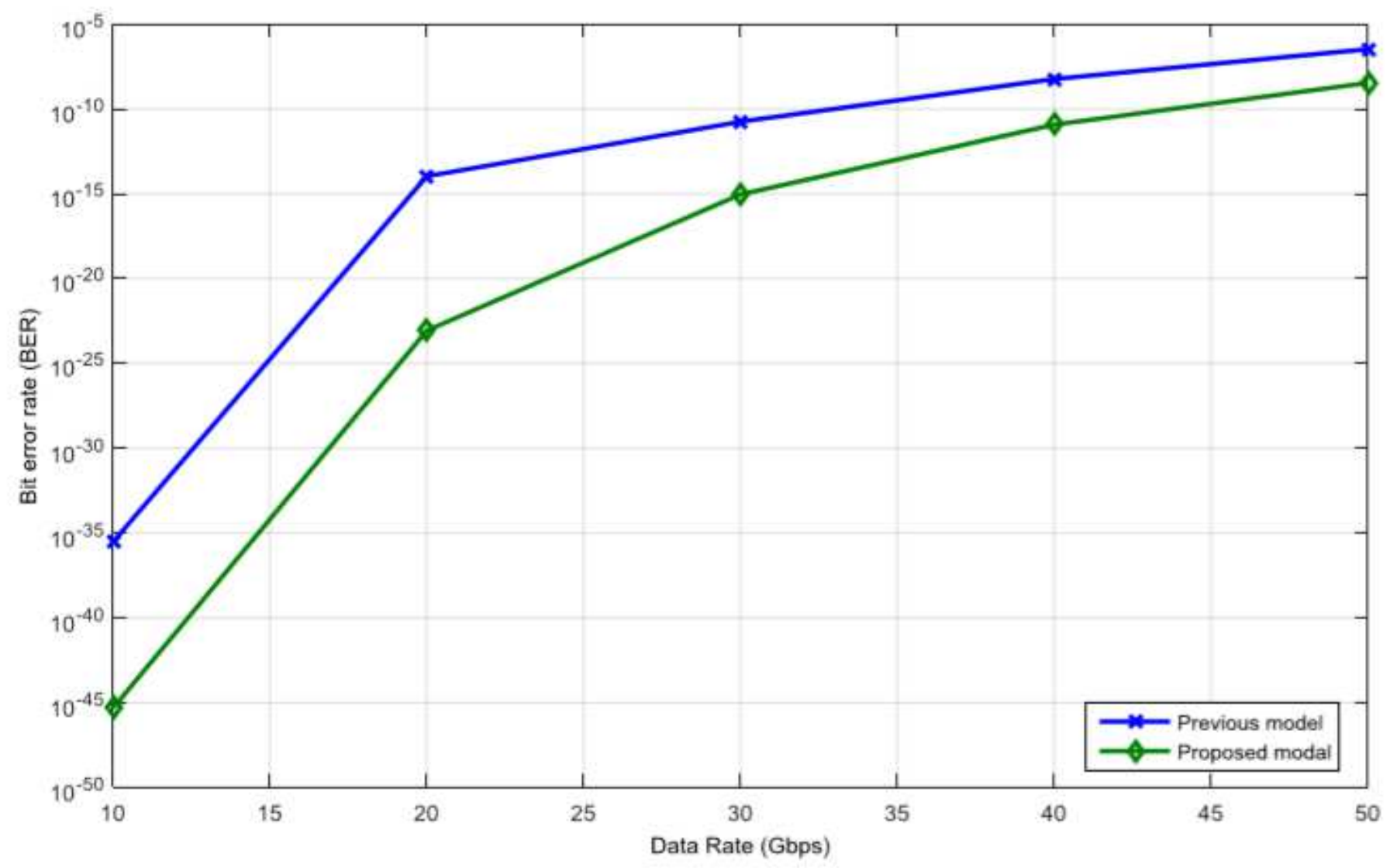

Figure 7

Minimum BER value versus data rate for $5 \mathrm{G}$ range applications using previous modal (without optical filter). 


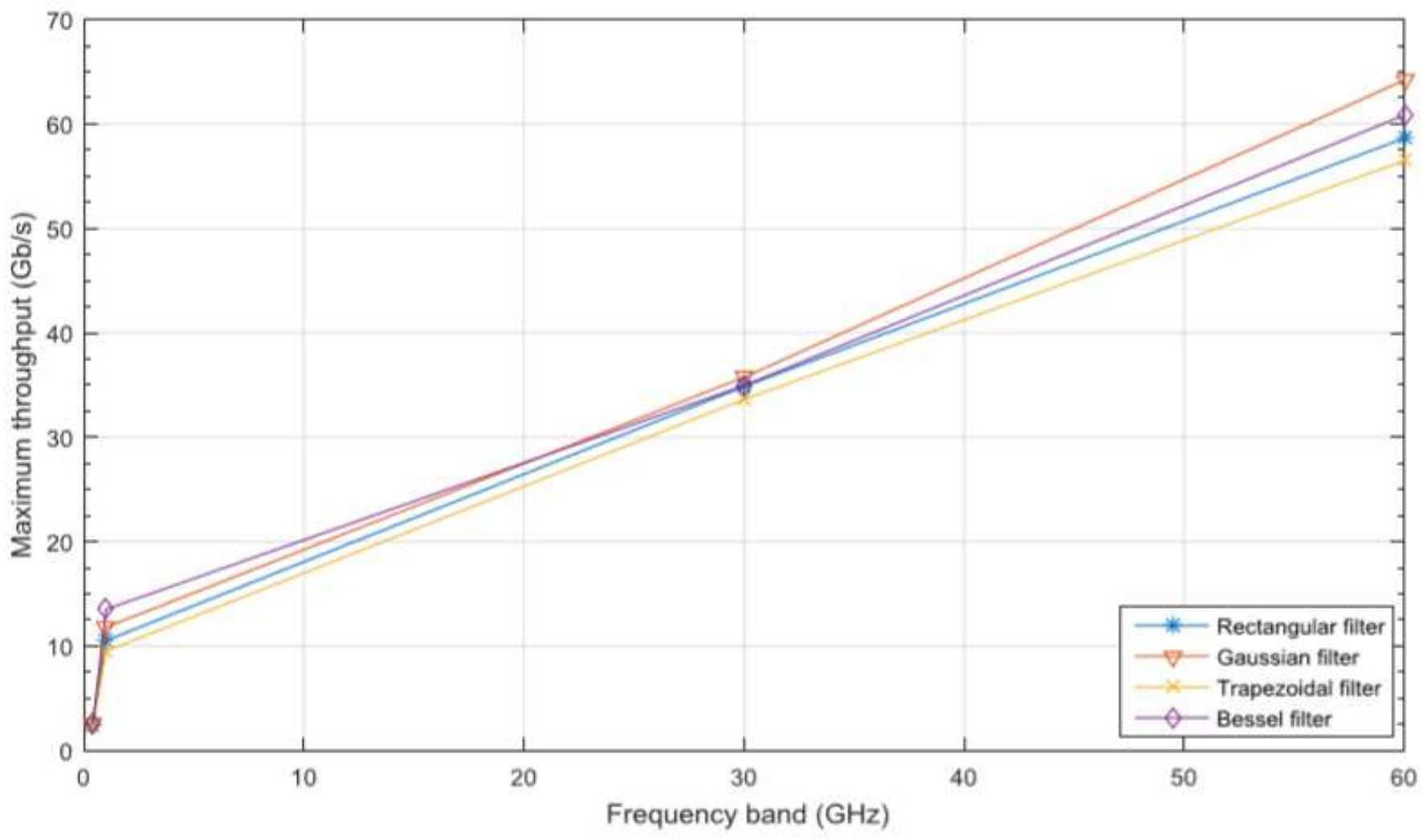

Figure 8

Throughput versus frequency band 


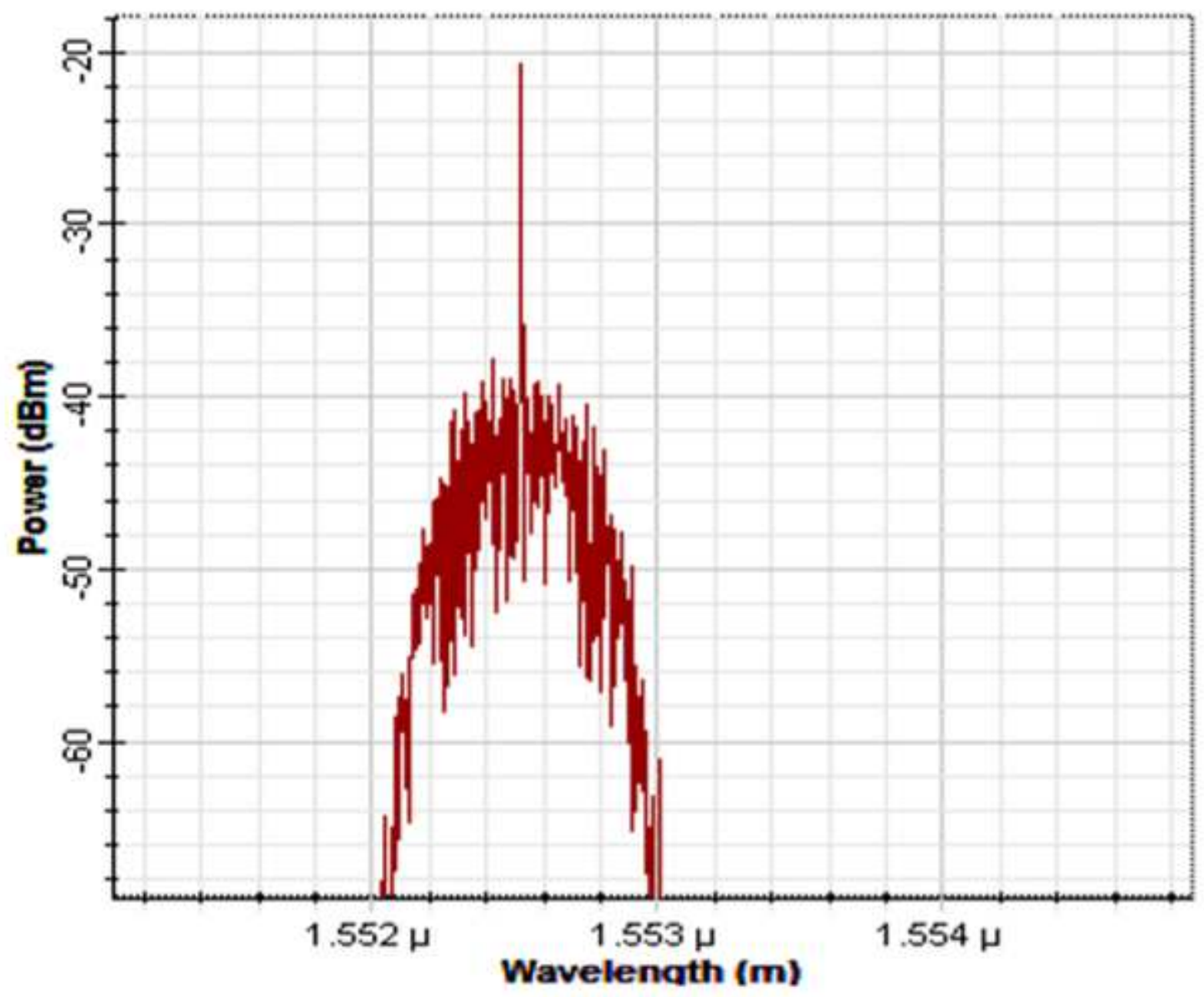

Figure 9

Rectangular optical filter received power versus wavelength. 


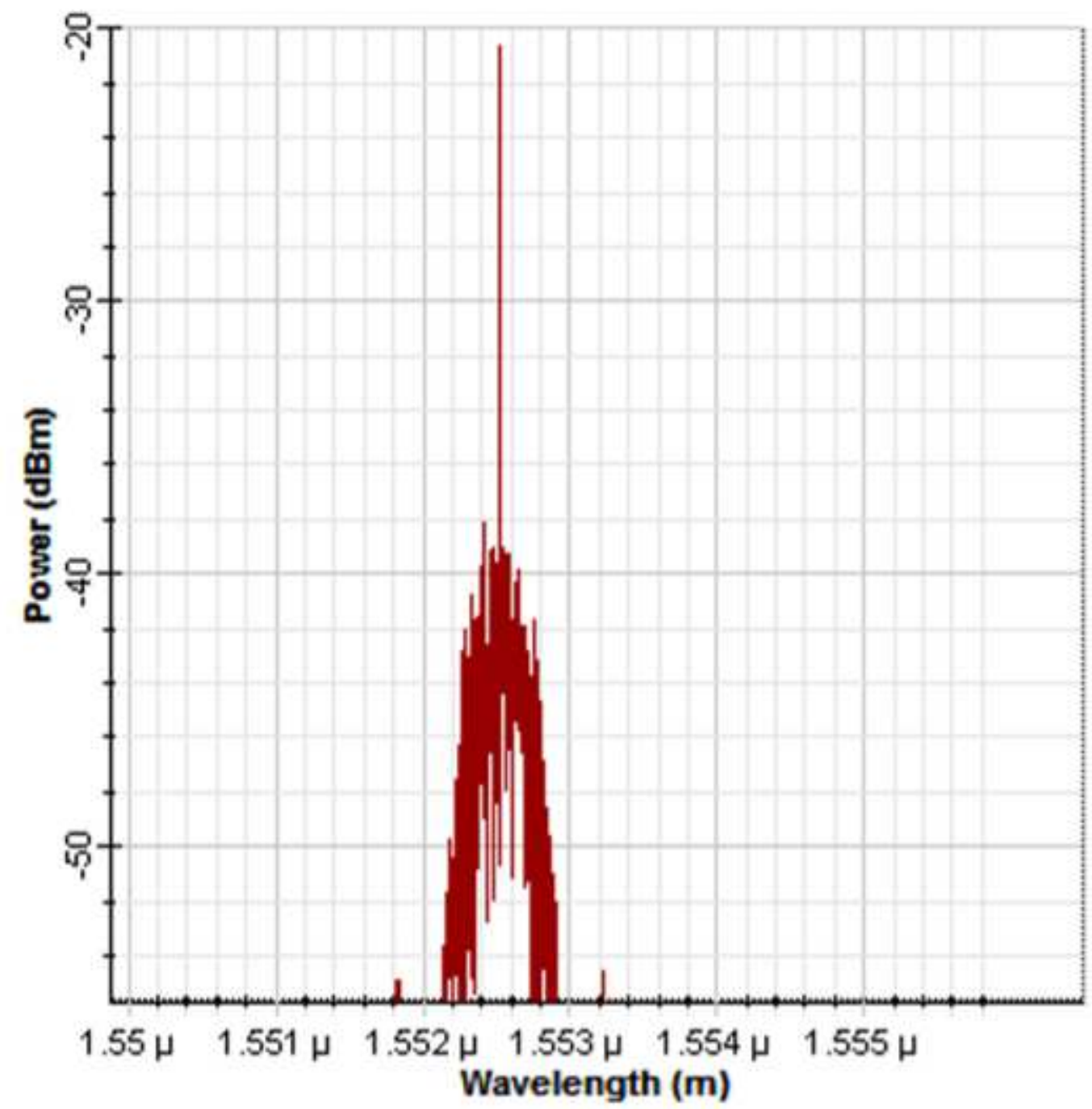

Figure 10

Trapezoidal optical filter received power versus wavelength. 


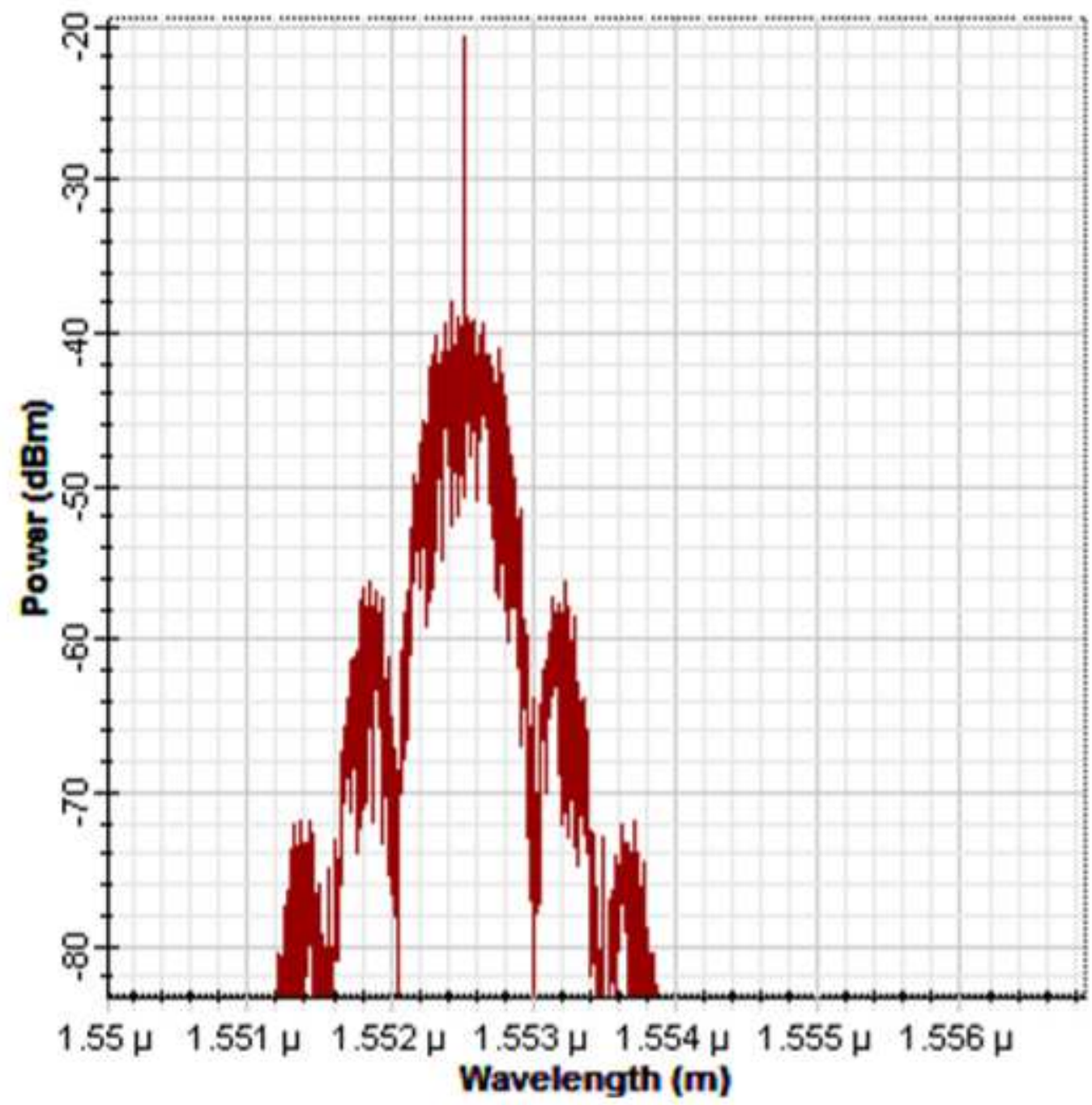

Figure 11

Gaussian optical filter received power versus wavelength. 


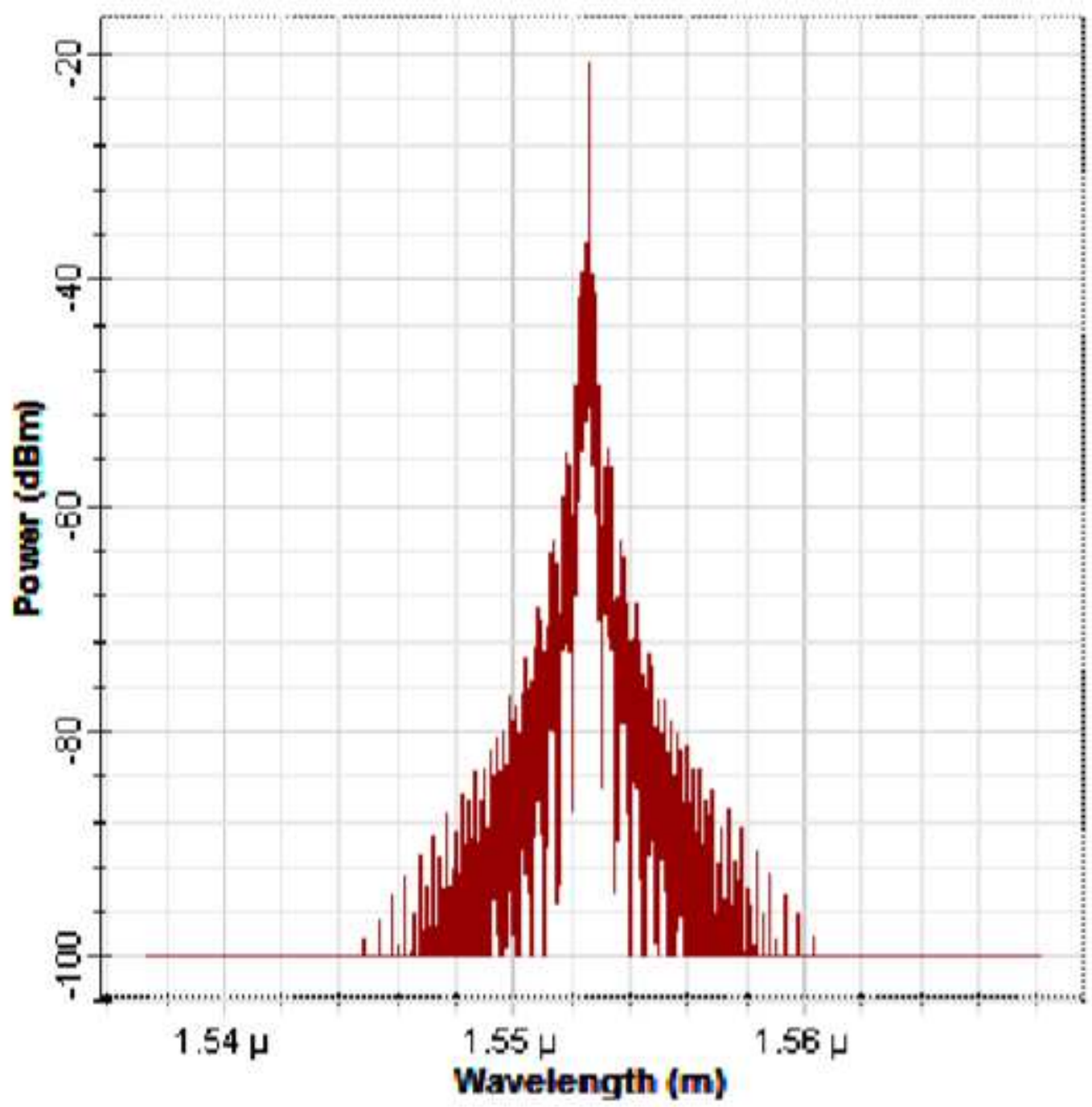

Figure 12

Bessel optical filter received power versus wavelength. 


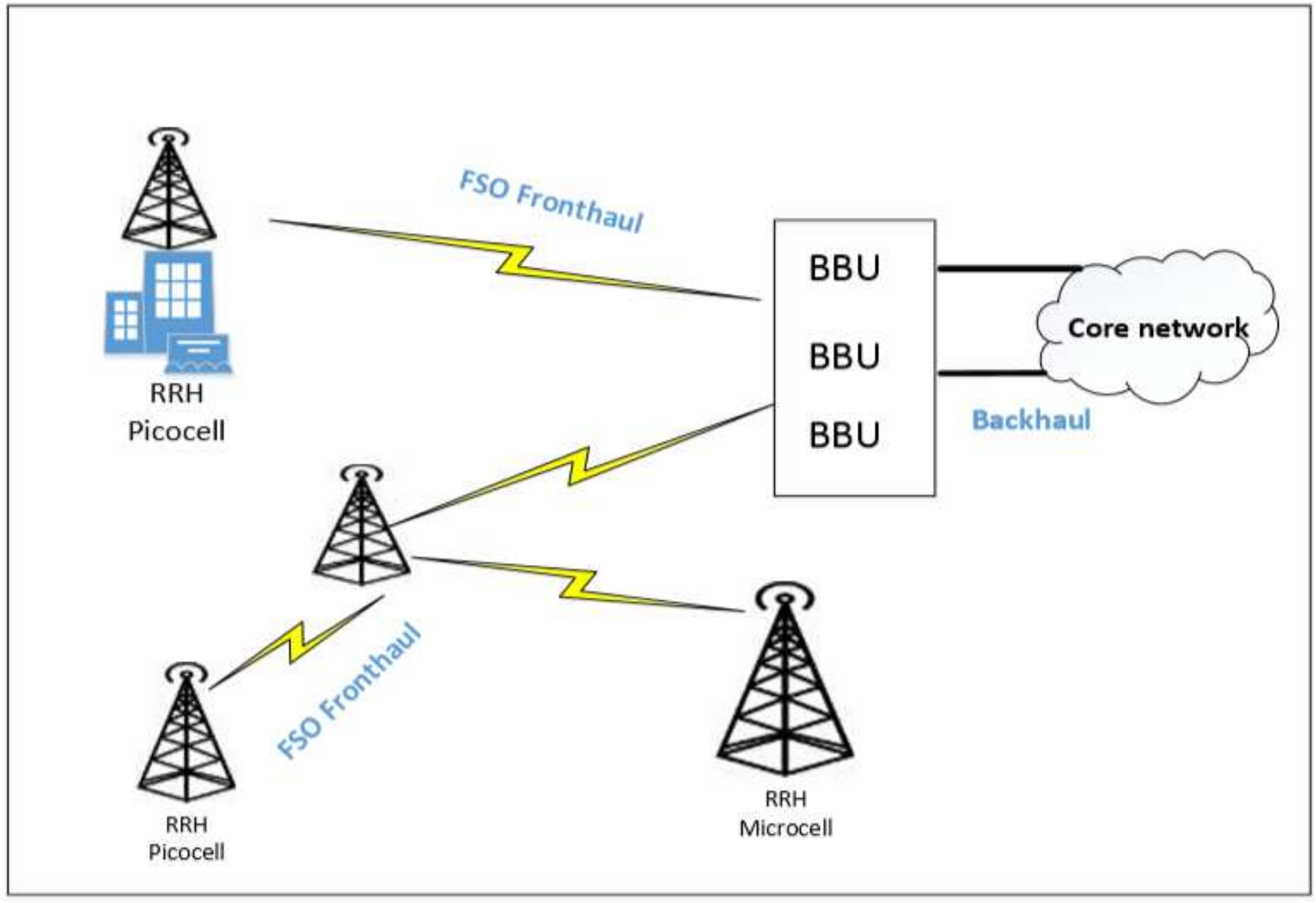

Figure 13

Application of FSO link in 5G networks 


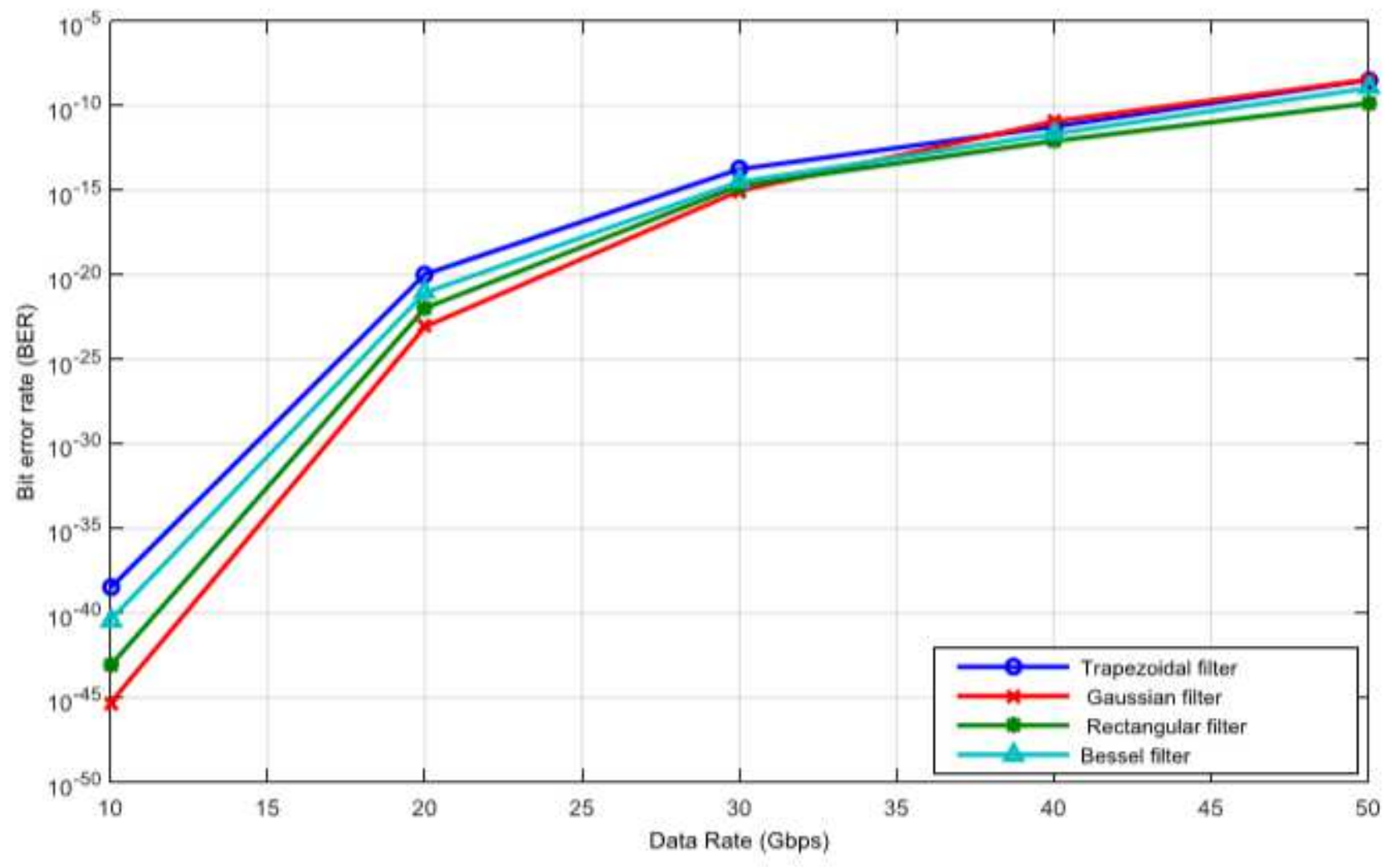

Figure 14

Minimum BER value versus data rate for $5 \mathrm{G}$ range applications using different optical filters. 